\title{
Estratégias de manipulação temporal no "Allegretto em Dó Menor D915" de Franz Schubert
}

\author{
Ernesto Hartmann
}

\author{
Universidade Federal do Espírito Santo | Brasil \\ Programa de Pós-Graduação em Música da UFPR | Brasil \\ Programa de Pós-Graduação em Música da UFMG | Brasil
}

\begin{abstract}
Resumo: o presente trabalho investiga em trinta gravaçôes do Allegretto em Dó menor D915 para piano de Franz Schubert (1827) realizadas entre 1939 e 2019 as estratégias de performance através da manipulação temporal empregadas por cada intérprete. Considerando que a obra em tela apresenta seu tema principal em três tonalidades distintas, busca verificar se há padróes entre estas estratégias e se elas se correlacionam com a época do registro. Para tal, define o conceito de período de acordo com Esther Scliar; realiza uma breve revisão da literatura a respeito das relaçôes entre manipulação do tempo e modulação na perspectiva de professores de piano (Lhevinne, Leimer e Gieseking, Paderevski e Fraser), compositores/teóricos (Schoenberg e Persichetti) e da psicoacústica (Parncutt); extrai os dados da segmentação dos extratos delimitados e discute-os. Como conclusão, verifica a presença de algumas relaçốes relevantes dentro do universo delimitado que articulam época de gravação com andamento e estratégias de intepretação.
\end{abstract}

Palavras-chave: Allegretto em Dó menor D915 para piano; Franz Schubert; Manipulação temporal.; Estratégias interpretativas; Modulação.

\begin{abstract}
: this work investigates the performance strategies associated with voluntary temporal manipulations present in thirty recordings released between 1939 and 2019 of Franz Schubert's Allegretto in C minor for piano (1827). Understanding that the work presents its theme in three different key levels, it aims to verify whether there is any relation between the date of recording and the Tempi/Performance strategies employed by the artists. To do so, it defines the concept of period according to Brazilian theorist Esther Scliar; performs a brief revision of the literature concerning the relations on performance and tonalities in the view of professors/performers (Lhevinne, Leimer e Gieseking, Paderevski and Fraser), composers/theorists (Schoenberg and Persichetti) and on Psychoacustics (Parncutt); extract the data form the segments of the recordings and discuss them. As a conclusion it verifies that, in fact, there is (as far as delimited by the thirty recordings) relevant relations that correlates tempo and strategies with the decades that the recordings took place.
\end{abstract}

Keywords: Allegretto in C minor for piano D915, Franz Schubert, Temporal manipulation, Performance strategies, Modulation. 


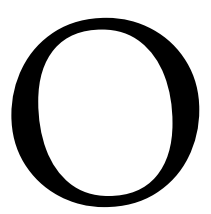

Allegretto em Dó menor D915 do compositor austríaco Franz Schubert, composto em abril de 1827 é uma obra que apresenta um problema interpretativo de grande interesse. Isso se dá em virtude da proposta de seu tema principal ser exposta em três tonalidades distintas ao longo da peça: Dó menor (tonalidade principal); Mi ${ }^{\mathrm{b}}$ Maior e Dó Maior. Ciente de que, mesmo no início do século XIX, a escolha das tonalidades de uma obra não se dava aleatoriamente, sendo permeada por uma longa e forte tradição de associações com determinados afetos, indaga-se qual ou quais estratégias alguns dos principais intérpretes empregaram no intuito de destacar cada um dos eventos em que o tema se apresenta em uma distinta tonalidade.

Assim sendo, este trabalho investiga - com foco nas estratégias de manipulação temporal ${ }^{1}-$ trinta gravações realizadas entre 1939 e 2019 desta obra². As gravaçóes foram selecionadas mesclando os registros de alguns intérpretes reconhecidamente especialistas na obra do compositor como Paul Badura Skoda, Alfred Brendel, Maria João Pires e András Schiff, com outros especialistas em instrumentos antigos (uma gravação de Paul Badura-Skoda e uma de Trudelies Leonhardt), além de outras de intérpretes que, mesmo não sendo especialistas na obra de Schubert, têm carreira consolidada e reconhecida (Grigory Sokolov; David Fray; Maurizio Pollini). Todas as gravações presentes são comerciais, com exceção das gravaçốes de Paul Lewis ao vivo na sala São Paulo em junho de 2013 e das de Grigory Sokolov, também ao Vivo em Amsterdam e Wiesbaden (2018 e 2019, respectivamente). Alguns intérpretes estão duplamente representados, como é o caso de Paul Badura-Skoda (1956/1988), Sviatoslav Richter (1961/1963), Paul Lewis (2011/2013) e Grigory Sokolov (2018/2019).

A tabela 01 apresenta todas as gravaçóes selecionadas para este trabalho:

TABELA 01 - Gravações selecionadas para análise das estratégias interpretativas.

\begin{tabular}{lcc}
\hline Ano & Artista \\
\hline 1939 & Arthur Schnabel \\
1947 & Ray Lev \\
1949 & Claudio Arrau \\
\hline
\end{tabular}

\footnotetext{
${ }^{1}$ Agógica e andamento.

2 Todas as gravações analisadas aqui estão disponibilizadas na plataforma de streaming YouTube. Contudo, conforme indicado nas referências completas deste trabalho, algumas já pertenciam ao meu acervo particular, porém, foram adquiridas nas plataformas de streaming pago das gravadoras.
} 
TABELA 01 (cont.) - Gravações selecionadas para análise das estratégias interpretativas.

\begin{tabular}{|c|c|}
\hline Ano & Artista \\
\hline 1956 & Badura Skoda \\
\hline $1957\left(\operatorname{aprox}^{3} ..\right)$ & Bruce Hungerford \\
\hline 1961 & Sviatoslav Richter \\
\hline 1963 & Sviatoslav Richter \\
\hline 1967 & Wilhelm Kempff \\
\hline $1968-1970$ & Gilbert Schuchter \\
\hline 1978 & Edith Vogel \\
\hline 1982 & Tessa Birnie \\
\hline 1985 & Richard Goode \\
\hline 1987 & Maurizio Pollini \\
\hline 1988 & Alfred Brendel \\
\hline 1988 & Paul Badura-Skoda (Fortepiano) \\
\hline 1990 & Andras Schiff \\
\hline 1994 & Pasquale Iannone \\
\hline 1995 & Stephen Kovacevic \\
\hline 1996 & Cyprien Katsaris \\
\hline 1998 & Maria João Pires \\
\hline 1999 & Thomas Larcher \\
\hline 2000 & Tamara Rumiantsev \\
\hline 2001 & Alexander Lonquich \\
\hline 2005 & Michel D’Alberto \\
\hline 2009 & David Fray \\
\hline 2010 & Trudelies Leonhardt (Fortepiano) \\
\hline 2011 & Paul Lewis \\
\hline 2013 (Brasil, São Paulo, junho) & Paul Lewis \\
\hline 2018 (13 de maio, Amsterdan) & Grigory Sokolov \\
\hline 2019 (24 de julho, Wiesbaden) & Grigory Sokolov \\
\hline
\end{tabular}

A relevância deste tipo de pesquisa reside na elucidação e compreensão de padrões ou estratégias interpretativas a partir dos registros reais de performances, sejam elas em estúdio de gravação, sejam ao vivo. Sistematizar estas estratégias, de modo a poder identificá-las e contabilizálas, relacionando-as ao seu contexto histórico, permite uma compreensão de grande valia tanto para o intérprete atual como para os interessados em pedagogia da performance.

Antigamente, o acesso a gravaçôes de grandes intérpretes era restrito. Mesmo existindo, a circulação destes registros dependia de um meio físico como o LP, a fita K7 e, posteriormente, o $\mathrm{CD}$, o que, frequentemente, dificultava sua disponibilização. Com a popularização da internet nos

\footnotetext{
${ }^{3}$ A data exata da gravação é desconhecida.
} 
anos 1990 e o nascimento das plataformas de streaming em meados da década de 2000 esse panorama foi alterado radicalmente. É praticamente impossível não escutar uma obra (exceto se ela for, em si mesma, uma obra rara) em um grande número de versóes, todas elas facilmente acessíveis. Esse novo paradigma torna impraticável certos hábitos, ainda arraigados em uma pedagogia da performance, e, particularmente, do piano, como o de uma suposta construção original da intepretação de uma determinada obra eximindo-se de escutar qualquer gravação dela, uma vez que todos estão expostos a apenas um clique de distância de uma plêiade de opções de interpretaçóes em qualquer nível, desde o amador até o profissional.

Igualmente, a simples construção da interpretação a partir de uma reflexão exclusivamente teórica, advinda da análise da peça, também não contempla todas as possibilidades, que, de fato, já existem e estão registradas em, aproximadamente, um século de indústria fonográfica.

Dessa forma, importa conhecer, examinar e categorizar, de forma a avançar o conhecimento acerca das práticas interpretativas a "opinião" dos intérpretes, opinião essa materializada em suas criações, ou seja, nos seus registros, uma vez que a performance ao vivo, caso não registrada, é efêmera.

Assim sendo, este trabalho indaga as seguintes questóes delimitadas ao estudo das manipulações temporais realizadas pelos intérpretes selecionados: Qual ou quais abordagens os intérpretes selecionados da obra em tela utilizam? Quais são as ferramentas que compõem essas abordagens? Elas obedecem a algum padrão temporal, ou seja, andamentos ou estratégias ocorrem majoritariamente ou não dentro de uma determinada década ou em determinados contextos?

No intuito de responder estas questóes, dentro dos limites dos trinta registros selecionados, extraio extratos de cada gravação contendo as apresentaçóes do tema em cada uma das tonalidades, analiso-os e comparo-os quanto a sua duração e categorizo as principais alterações em seis estratégias observáveis. Estas são sustentadas pelo andamento médio, ou seja, o quociente entre a duração do extrato e seu comprimento. Além, disso, busco identificar e ilustrar graficamente se o tempo médio aumentou, diminuiu ou manteve-se constante ao longo das décadas.

Como principal limitação para estas últimas indagaçóes, apenas comparo os dados referentes às décadas de 1960 e 1980-2010, posto que as gravações das décadas de 1930; 1940; 1950 e 1970 estão em número insuficiente para se obter qualquer conclusão significativa. 
Destarte, o trabalho se estrutura, inicialmente, a partir da definição do vocabulário analítico essencial para denominação das estruturas, onde fundamento-o no conceito de Período da teórica brasileira Esther Scliar; seguido de uma discussão sobre o papel estrutural da modulação/alternância de tonalidades; da análise da parte A da forma ternária do Allegretto D915 em Dó menor de Schubert, da explanação detalhada do método empregado para obtenção e exame dos dados; da discussão dos dados e das considerações finais.

\section{O Período}

Há uma vasta literatura a respeito da estrutura periódica na música e, mais, precisamente, nas obras dos compositores da Primeira Escola de Viena. Para este trabalho, emprego a definição e terminologia proposta por Esther Scliar que descreve satisfatoriamente a estruturação concebida por Schubert nas apresentações temáticas do Allegretto em Dó menor D915.

"Duas ou mais frases formam um período" (SCLIAR, 2019, p. 18),

O período é o agrupamento mais completo da fraseologia, correspondendo, muitas vezes, a uma parte da estrutura. [.] sob o ponto de vista quantitativo, os períodos se classificam em binários, ternários ou duplos. $\mathrm{O}$ condicionamento destas estruturas depende basicamente do princípio da complementação, princípio este que se define em função do relacionamento entre o antecedente e o consequente. $\mathrm{O}$ antecedente enuncia uma proposição cuja cadência não é definitiva. Esta condição está relacionada com o caráter da proposição, cuja oração é geralmente interrogativa, pois finaliza com a cadencia suspensiva. O consequente complementa o antecedente e, portanto, quando esta oração é interrogativa, o subsequente pontua com a cadencia conclusiva. Este paradigma é mais característico nos períodos binários, especialmente naqueles que do ponto de vista qualitativo são afirmativos (paralelos) (SCLIAR, 2019, p. 52)

No caso do Allegretto D915, a primeira frase (Antecedente do Período a) conclui com a Tônica, aparentemente negando a proposição formulada pela autora. Todavia, Scliar define algumas exceções, dentre as quais, está contemplada essa situação em particular,

O Antecedente pode finalizar com a cadencia autêntica quando:

1. A função tônica e enfatizada.

2. O consequente modula, finalizando em cadência autêntica ou suspensiva.

3. Os membros de frase do antecedente são iguais ou semelhantes (SCLIAR, 2019, p. 53). 
Essas três condições descrevem precisamente o que ocorre nos oito primeiros compassos da obra em tela, pois a primeira frase (Antecedente) se encontra em Dó menor, iniciando com um arpejo de I que perdura por quase que integralmente o primeiro compasso; segue-se uma Consequente que articula o mesmo material (“membros de frase iguais ou semelhantes”) na região de III (Homônimo - Mi ${ }^{\mathrm{b}}$ Maior), sendo, portanto, nesse contexto, modulante.

Ainda, para Scliar, "Os períodos mais afirmativos caracterizam-se pela correspondência entre os membros de frase. Sem embargo, são também considerados afirmativos aqueles períodos cujo(s) Consequente(s) apenas se inicia(m) com elemento(s) homogêneo(s)" (SCLIAR, p. 53), o que, novamente, trata-se do caso.

Mais adiante, neste trabalho, apresento uma análise detalhada dos trechos da obra que constituem o objeto desta pesquisa.

\section{A modulação como fator estrutural relevante}

Claudiney Carrasco destaca a relevância do processo modulatório e sua articulação com o ritmo na música tonal, ao afirmar que,

a atenção do ouvinte é sustentada não apenas pela organização [de uma] macroestrutura formal, mas também por elementos médios e microestruturais, ou subsidiários, como os denomina Esslin. Esses elementos podem ser encontrados nos diversos movimentos cadenciais, nas variaçóes de andamento, na mudança de atividade rítmica (valores longos, valores curtos), nas articulações, dinâmicas, texturas e, especialmente, no jogo das funções harmônicas (CARRASCO, 1992, p. 147).

No contexto descrito pelo autor é razoável considerar que os intépretes adotem abordagens e estratégias que possam realçar eventos modulatórios significantes dentro de uma determinada peça, obviamente, considerando as implicações estilísticas inerentes a própria obra. Destarte, os intépretes, dentre várias outras ações, desempenham um papel análogo ao de um agente de uma narrativa articulando o discurso musical a uma ação dramática.

Se, concomitantemente à consolidação do que compreendemos como o sistema tonal, a partir do século XVII, a teoria dos afetos promoveu claras, porém, subjetivas associações entre modos e tonalidades (teoria que, em si, resgata ideias muito anteriores a era moderna, posto que se 
fundamentam na interpretação dos princípios já propostos por Platão na República-399, e, posteriormente, discutidos por Aristóteles), mais recentemente, pesquisas interdisciplinares entre música e psicologia almejaram elucidar se essas associações, e, em particular, as relações entre claroescuro/modo Maior-Modo Menor/Bemol-Sustenido se sustentam cientificamente.

Diversos autores discutem esse tema nessa perspectiva específica. Dentre eles é possível destacar os trabalhos de John Sloboda e Richard Parncutt. Richard Parncutt, em seu livro Harmony: a Psychoacoustical Approach de 1988-89 nos informa sobre o estado da ciência ao final da década de 1980,

as diferenças entre os modos maior e menor foram centrais para o significado emocional da música diatônica, ao menos desde a Renascença. Desde que mantidas iguais em um determinado trecho timbre, textura, tempo, etc. o modo maior é supostamente mais apropriado para exprimir emoçóes positivas (alegria, clareza, confiança, vitória, etc...) e a música em modo menor para emoções negativas (tristeza, escuridão, derrota, tragédia, etc...). É indiscutível que o ouvinte ocidental é sensível as conotações emocionais do modo maior e menor; pesquisas recentes chegaram ao ponto de demonstrar a conexão entre preferência por maior ou menor e dependência oral. Contudo, as origens das conotaçôes emocionais dos modos maiores e menores é ainda obscura (PARNCUTT, 1989, p. 71).

Contudo, o autor nos adverte acerca de questóes que dizem respeito diretamente a progressóes e modulaçôes dentro de um determinado contexto,

A estrutura tonal de uma peça deve ser firmemente estabelecida antes de podermos atribui-la uma característica 'maior' ou 'menor'. Destarte, estudos experimentais sobre os significados emocionais dos intervalos (Maher, 1980) e sobre a percepção das características 'maior' ou 'menor' das tríades (Crowder, 1985) não envolveram ainda contextos tonais claros e não ambíguos, não nos permitindo conclusões muito precisas sobre os significados emocionais de progressóes tonais especificas como gostariam os teóricos (PARNCUTT, 1989, p. 72).

De fato, abunda na literatura exemplos onde se estabelece direta ou indiretamente, explícita ou implícitamente, relações seja entre os modos (Maior/Menor), seja entre as tonalidades.

Aproveitando as três tonalidades em que se apresenta o tema do Allegretto D915 em Dó menor de Schubert, ilustro na tabela 02 duas descriçóes. A primeira data de 1713 e é de Mattheson, sendo extraída de uma de suas principais obras teóricas, Das Neu-eröffnete Orchestre. A segunda, encontra-se no Ideen zu einer Ästhetik der Tonkunst, publicado em Viena em 1806 (data próxima à 
da composição do Allegretto) de Christian Friedrich Daniel Schobart. Vale recordar que ambas as obras gozaram de grande prestígio enquanto tratados musicais em suas épocas.

TABELA 02 - Comparação entre os afetos das tonalidades de Dó menor, Mi ${ }^{\mathrm{b}}$ Maior e Dó Maior

\begin{tabular}{|c|c|c|}
\hline Tonalidade & $\begin{array}{c}\text { Mattheson } \\
\text { (Das Neu-eröffnete Orchestre Hamburg, } \\
\text { 1713) }\end{array}$ & $\begin{array}{c}\text { Schubart } \\
\text { (Ideen zu einer Ästhetik der Tonkunst Wien, } \\
1806)\end{array}$ \\
\hline Dó Maior & Alegre, Impertinente/ rude e atrevida & Inocente \\
\hline Dó Menor & Suave e Triste, Ameno & Declaração de amor e queixa amorosa \\
\hline Mi $i^{\mathbf{b}}$ Maior & Coisas Sérias, Patético, Lamento e Religioso & $\begin{array}{l}\text { Tonalidade de devoção e da conversa íntima com } \\
\text { Deus. Expressão da trindade com seus três bemóis. }\end{array}$ \\
\hline
\end{tabular}

Em particular, para estas três tonalidades, Mattheson e Schobart apresentaram percepções similares (ao menos, não irreconciliavelmente antagônicas), situação que não ocorre com outras tonalidades, principalmente, as menos empregadas em suas épocas. Há de se considerar também diversas questões que podem conduzir a divergências, como diferenças de afinação, tópicas específicas de cada obra etc... (evidentemente, o afeto de uma Sarabanda em Dó menor é distinto do afeto de uma Giga na mesma tonalidade).

Não obstante, é notável a atribuição de um sentimento teísta à tonalidade de $\mathrm{Mi}^{\mathrm{b}}$ Maior, independentemente de sua armadura simbolicamente ser uma possível representação da trindade cristã ${ }^{4}$. Desta forma, indaga-se se a sucessão de uma mesma ideia apresentada nestas tonalidades estaria sujeita a variações significativas de dinâmica e tempo (dentre, evidentemente, a manipulação de outros parâmetros). Se, de fato, a sugestão de uma dinâmica pode ser proposta pelo prórpio compositor e, dentro das suas limitaçôes, é facilmente incorporada à notação, por outro lado, sutis alterações de tempo, que podem ser decisivas para destacar cada um dos afetos são de mais difícil representação. É de amplo conhecimento que elas são um dos recursos mais eficientes e indispensáveis disponíveis para o intéprete deste repertório.

A flutuação do tempo, a liberdade quando aplicada a um trecho maior, melhor se identifica com o conceito de rubato "alteração expressiva do ritmo ou tempo" o tempo roubado. Sobre o Rubato reproduzo duas das diversas recomendaçốes deixadas por Ignaz Paderevski e publicadas por

\footnotetext{
${ }^{4}$ Que, ironicamente, talvez limitaria essa "religiosidade" apontada pelo autor à exclusivamente a religiosidade cristã.
} 
Henry Finck em 1929,

O tempo rubato é um potente fator na oratória musical e todo intérprete deve ser capaz de usá-lo judiciosamente e com habilidade, visto que ele enfatiza a expressão, introduz a variedade e infere vida em uma execução mecânica. O rubato amacia a dureza das linhas, desenha os ângulos estruturais sem arruiná-los, dado que sua ação não é destrutiva: ao contrário, ele intensifica, refina e idealiza o ritmo (PADEREVSKI 2001, p. 3)

e

Não há algo como ritmo absoluto. No decorrer dos desenvolvimentos dramáticos de uma composição musical, os temas iniciais alteram o seu caráter e, consequentemente, o ritmo também se altera. Em conformidade com este novo caráter o ritmo deve ser enérgico ou elástico, constante ou caprichoso (PADEREVSKI 2001, p. 3).

Além de Paderevski, outros importantes autores como Leimer e Gieseking, e Alan Fraser também comentam sobre a necessidade do Rubato. De acordo com Leimer e Gieseking,

Para as modificaçóes agógicas, ou seja, aquelas pequenas alterações do movimento que o compositor não indica, visto que são deixadas ao bom gosto do intérprete, vale em geral o princípio de que até o ponto culminante se produz uma certa aceleração e a partir da própria nota do ponto culminante se inicia um leve ritardando que se estende até a última nota da frase, sobretudo nas finalizações femininas (LEIMER, GIESEKING 1938, p. 52).

Para Fraser,

Pode parecer estranho, mas uma qualidade fundamental do ritmo é que ele não é metronômico [...] o fato mais impressionante é que o ritmo saudável sempre divergirá da regularidade metronômica por duas razões cruciais: 1) a natureza da respiração da frase e 2) a discriminação dos níveis hierárquicos rítmicos: a diferença entre tempos fortes e fracos (FRASER, 2003, p. 303).

Fica evidente nestes dois depoimentos que a relação entre as flutuaçôes do ritmo (andamento) imiscuem-se com a estrutura do texto musical, seja em proporçôes menores como a frase ou em maiores como a própria forma. Pontos culminantes e variações no tema (que, evidentemente incluem o caso que aqui discuto, a transposição da ideia principal de uma obra para outra tonalidade/afeto), são eventos que demandam essa especial atenção por parte do intéprete, manifestada através da manipulação agógica.

Ainda, sobre esta questão, Josef Lhevinne, importante pianista e professor de piano do início do século $\mathrm{XX}$, expressa sua opinião sobre a relação entre as estruturas tonais da obra e suas 
consequências na interpretação, particularmente no que diz respeito ao ritmo, e que pode ser apreciada na seguinte citação de seu célebre livro Basic principles in pianoforte playing,

Frequentemente eu tive alunos que me procuraram para instrução que eram capazes após grande esforço preparar uma, duas ou no máximo três peças virtuosísticas, peças tão avançadas como os Concertos de Tchaikovski e de Liszt, mas que quase nada sabiam sobre o que estavam tocando. Não compreendiam as modulaçóes e suas implicaçôes na interpretação de obras primas de tamanha complexidade e dificuldade sendo, portanto, ignorantes a respeito da música (LHEVINNE, 1924, p. 7).

Uma das maiores preocupaçóes de Lhevinne era com o ritmo, elemento essencial na interpretação. Ele compreende que o ritmo é um parâmetro fundamental que, através do Rubato, possa ser alterado de forma a realizar e destacar os diversos afetos provocados pelos processos modulatórios de uma dada obra.

Portanto, para Lhevinne, o ritmo deveria ser sistematicamente trabalhado pelo pianista (intérprete) de forma, que suas mínimas inflexôes estivessem sob seu absoluto controle e a serviço de um propósito exclusivamente articulado ao texto musical. Lhevinne esclarece que isso não significa uma cega reprodução da notação, e sim a capacidade de, como dizia Haslam (1911) aplicar as "Variações do tempo, o Ritardando, Accelerando e Tempo rubato, como auxílios legítimos demandados pela expressão, pois seu uso é determinado pelo julgamento e correto gosto musical”.

\footnotetext{
É muito difícil ensinar ritmo. Ele deve ser sentido. Ele é, até certo ponto contagiante, e, por isso mesmo o estudante que frequenta concertos e escuta boas interpretaçóes em comparação às várias 'máquinas de reprodução sonoras' tem uma grande vantagem [...] é praticamente impossível descrever o que é ritmo. De forma alguma é uma questão meramente de acentos. Eu conheço alunos que tocam a Marcha Militar de Schubert com cada acento corretamente articulado, não obstante soam mais como uma marcha de soldados de chumbo do que de soldados vivos (LHEVINNE, 1972, pp. 6-7).
}

Destaco que, o que Lhevinne denomina por ritmo, aqui, refere-se exatamente à flutuação do tempo ou, mais genericamente, Rubato, correspondendo ao conceito de agógica que, segundo o Grove Dictionary of Music and Musicians, é uma qualidade de expressão e, particularmente de acentuação. Esta qualidade está relacionada com as variações de duração (ritmo) ao invés da dinâmica. Trata-se, evidentemente, da possibilidade de alterar sutilmente essas durações, produzindo pequenas alteraçóes nos valores, visando destacar um determinado ponto ou momento 
específico da obra. Desta forma, conclui-se que esta é uma estratégia indissociável da tradição performática do repertório no qual se inclui o Allegretto D915, onde modulaçóes impactam decisivamente nestas variaçóes.

Similarmente àqueles que se dedicaram a discutir os problemas na perspectiva de intépretes ou da pedagogia do instrumento, os compositores também se manifestaram a respeito dos processos modulatórios, sempre enfatizando seu impacto estrurtural nas obras.

Schoenberg, por exemplo, dedicou-se a descrever detalhadamente as relações entre as tonalidades (mesmo que em uma perspectiva completamente esvaziada de seu conteúdo afetivo, e quase que integralmente técnica) em sua importante obra Structural Functions of Harmony, e, mesmo, em seu tratato Teoria da Harmonia - ao nos advertir que seu método de estudo, essencialmente, se fundamenta na repetição dos modelos observados nas obras dos grandes mestres, e que nestas, a modulação ocorre quase que "exclusivamente através de um processo cuidadosamente preparado" (SCHOENBERG, 2001, p. 15) - tratou de catagorizar as modulações à tonalidades próximas ou vizinhas de forma distinta. Isso pode ser inferido pela seguinte afirmação presente no Tratado:

Os antigos mestres limitavam-se em geral - mesmo nas partes correspondentes ao desenvolvimento -, a modular somente às tonalidades mais afins. Modulações a tonalidades remotas, pelo contrário, apresentam-se com frequência através de meios bruscos, inesperadamente, sem preparação harmônica, como surpresa (SCHOENBERG, 2001, p. 402).

Mesmo os reflexos da subjetiva (porém, "clínica”) noção de claro escuro associadas aos modos e as tonalidades ainda estão presentes na literatura teórica do século XX. Em Harmonia do Século $X X$, Vincent Persichetti, ao discutir a tensão entre as relações tonais, fundamenta-se nas quantidades de bemóis e sustenidos, propondo, a partir desta, uma ordenação de natureza claro/escuro ${ }^{5}$,

Os modos (escalas a partir de um polo referencial-tônica) podem estar ordenados eficientemente de acordo com a suas relações de tensão. Um maior número de bemóis aplicados a uma escala modal em uma tonalidade particular produzirá um modo mais 'sombrio', o Lócrio. Diminuindo os bemóis 'e, portanto, adicionando sustenidos' na ordem diatônica de escrita se produzirá uma ordem de modos desde o mais 'sombrio' ao

\footnotetext{
${ }^{5}$ Nesta tradução, sinônimos do par antitético “sombrio/brilhante”.
} 
mais 'brilhante' [...] dentro desta ordem existe uma gama de modos a disposição do compositor sendo possível um controle definido da formação de escalas e de suas qualidades inerentes (PERSICHETTI, 1961, p. 33).

De posse destas considerações é possível presumir o papel e o impacto da utilização de modulações ou regiôes dentro de uma obra, sobretudo, quando esta é monotemática, como no caso em discussão. Após a análise da peça, elenco qual ou quais as soluções encontradas pelos intérpretes das gravações selecionadas, buscando extrair algum ou alguns padrões recorrentes.

\section{Análise da seção A do Allegretto D915 em Dó menor para piano de Franz Schubert}

Como compositor de transição entre o período clássico e o período romântico, Schubert compôs diversas pequenas peças para piano que, se de certo modo ainda estão nitidamente atreladas à forma e estrutura clássica, em seu conteúdo já denotam uma expressividade e discursividade romântica, demandando do intérprete um profundo senso de equilíbrio e conhecimento estilístico.

O Allegretto D915 (abril de 1827) é um excelente exemplo deste tipo de obra. Incialmente composto inspirado na morte de Beethoven e com fortes possibilidades de unir-se ao grupo que hoje conhecemos como 6 Momentos Musicais D780 ou op.94 (182?-1828) - obra que estava sendo composta por Schubert na ocasião - estrutura-se como uma grande forma ternária ABA (AllegrettoTrio-Allegretto da capo) em Dó menor, sendo que seu Trio encontra-se na tonalidade da Submediante (Láb Maior). Para este trabalho concentro-me apenas na seção A (o Allegretto propriamente dito) que, por si mesma, é uma forma ternária aba' de 38 compassos $^{6}$. Neste trabalho não analiso nem discuto o Trio.

Do compasso 1 até o compasso 8 articula-se um período binário afirmativo (SCLIAR) com duas frases paralelas (mesma proposta). Estas frases já impõem um percurso harmônico definido, pois, a primeira, centra-se claramente na harmonia I-V de Dó menor e, a segunda, na I-IV-V-I de $\mathrm{Mi}^{\mathrm{b}}$ Maior - Tonalidade relativa. Estes oito compassos são imediatamente repetidos nos compassos 9-16.

\footnotetext{
${ }^{6}$ A fórmula de compasso é $6 / 8$.
} 
A figura 01 ilustra este período com sua proposta construída sobre a tríade da tônica, prevalecendo os intervalos disjuntos e a cadência, privilegiando as conjunçóes e realizando movimento descendente na direção da Tônica.

Ainda, as estruturas cadenciais de ambas as frases são construídas sobre um Schema que, Robert Gjerdingen, define como Prinner, ou seja, uma progressão melódica por graus conjuntos iniciando em 6 e terminando em 3 (GJERDINGEN, 2007, p. 365). No primeiro período do D915, essa sequência Prinner é apresentada, primeiramente, em Dó menor (c.3-4) e conclui evasivamente em $1^{7}$, promovendo uma cadência conclusiva já na Antecedente (realçado pelo fato da textura ser integralmente em uníssono) e, logo em seguida (c.7-8), na Consequente, harmonizada em $\mathrm{Mi}^{\mathrm{b}}$ Maior (o que a descaracteriza).

Essa tonicalização (ou modulação) para a tonalidade relativa, promovendo a apresentação da ideia temática principal em outra tonalidade relacionada por terças menores ou homônima - efeito tipicamente schubertiano -, é enfatizada pela mudança de textura. O que, na Antecedente, se apresenta em uníssono, aqui, na Consequente, além da dinâmica pp, apresenta-se em melodia com acompanhamento de acordes I-IV $-\mathrm{I}^{6 / 4}-\mathrm{V}$-I (de $\mathrm{Mi}^{\mathrm{b}}$ Maior), com uma bordadura de ${ }^{\mathrm{b}} 6 \mathrm{em} \mathrm{I}$ (c.5), grafada (adequadamente) como Dób, atestando a intenção do compositor de, factualmente, modular e cadenciar conclusivamente nesta tonalidade. A sequência Prinner, com esta rearmonização, agora torna-se um 4-3-2-1, onde o 1 é deslocado para o registro uma oitava acima. Esse mesmo recurso é empregado nos compassos 29-32 (a’) quando essa mesma Antecedente se apresenta em Dó Maior, estabelecendo uma clara diferenciação entre a apresentação na Tonalidade/modo original e nas outras tonalidades/modo.

\footnotetext{
${ }^{7}$ O que é paradoxal, uma vez que 1 é a conclusão, que, no Prinner, deveria ser apenas parcial, pois ele termina com 4-3.
} 
FIGURA 01 - Schubert Allegretto em Dó menor D915, c.1-8. Período a. em laranja o Prinner.

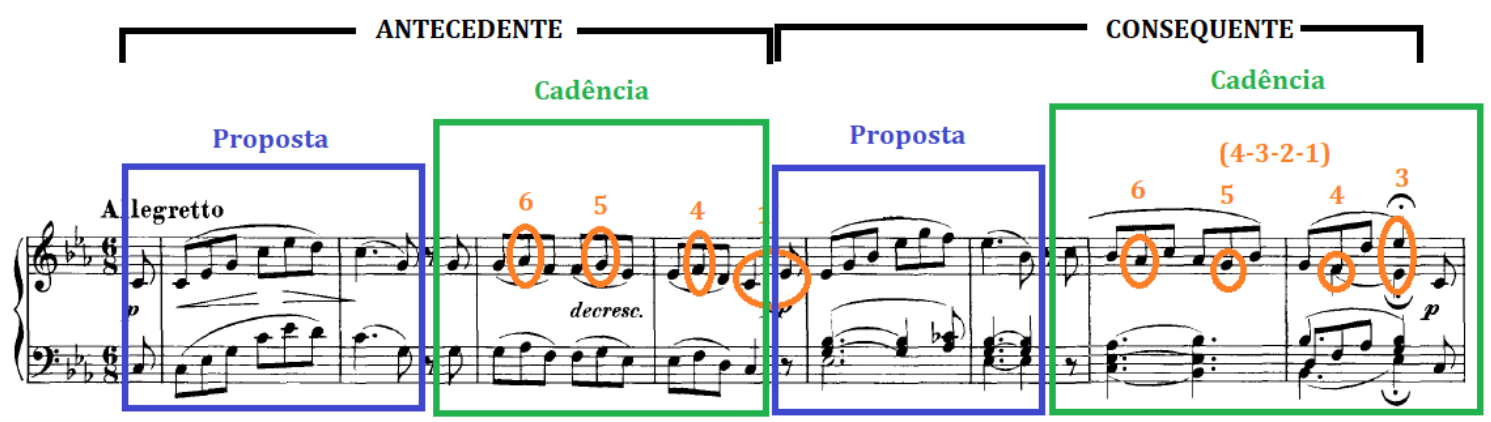

Segue-se ao a, como elemento de contraste e ligação ao a', um pequeno cânone totalmente centrado na harmonia de $\mathrm{V}^{9 b}$. Este cânone é liquidado pela repetição de sua ideia principal em uníssono (c.22) ao qual se sucedem dois acordes construídos sobre o pedal de Sol ${ }^{8}$ (V de Dó menor), Dominante da Dominante de Dó menor e Dominante de Dó menor, respectivamente nos c.27 e 28. Trata-se, este conjunto todo, da parte b (c.17-28), cuja função é oferecer contraste e, simultaneamente, afirmar a tonalidade de Dó menor por meio de sua Dominante 9 (figura 02).

FIGURA 02 - Schubert Allegretto em Dó menor D915, c.17-24. Ponte sobre V (parte b).

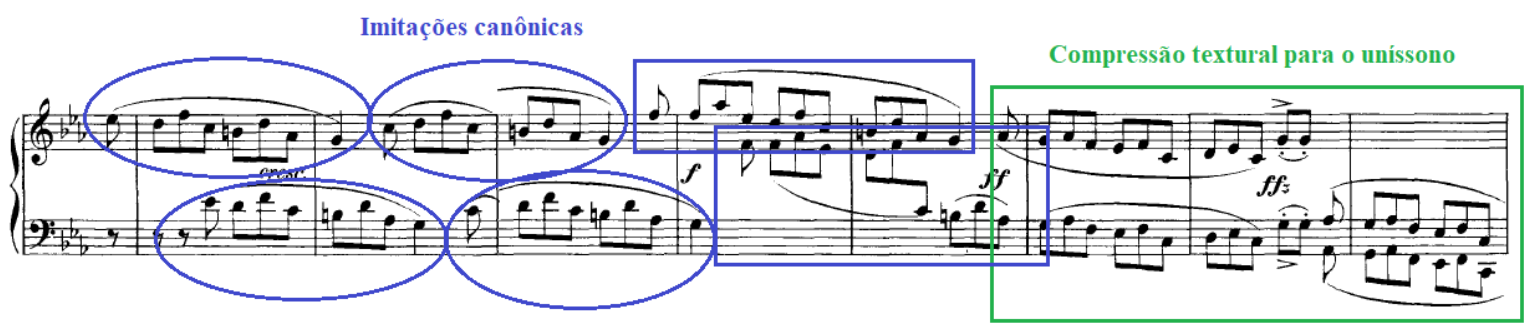

A recapitulação da seção a se dá de forma alterada. A mais relevante alteração é a utilização literal do mesmo material da frase Consequente (c.5-8) agora transposta para a tonalidade da tônica, porém, em modo maior (Dó maior) nos compassos 29 a 32, sendo, portanto, aqui, articulada como frase Antecedente. A frase Consequente é totalmente reconstruída e ampliada, partindo da, já familiar, textura em uníssono e conduzindo o motivo principal até um ponto culminante (c.35) em $\boldsymbol{f f}$, de onde inicia um rápido movimento descendente que conclui em uma textura mais densa

\footnotetext{
${ }^{8} \mathrm{Na}$ voz superior, promovendo uma interessante dissonância.

9 Igualmente ao Prinner, um Schema, que é definido por Gjerdingen (2007) como Ponte - um grande pedal da Dominante.
} 
(duplos dobramentos em terças). Assim, realiza esta frase Consequente uma síntese das texturas já apresentadas (uníssono e acordes como acompanhamento), encerrando o discurso de forma satisfatória tanto parcialmente (na primeira vez antes do Trio), quanto definitivamente (no da capo). A figura 03 ilustra a ampliação da frase e a presença do Dó maior na recapitulação de a (a'). A cadência final é reforçada com o emprego do acorde de 6ㅁnapolitana como preparação à $V$ (c.36).

FIGURA 03 - Schubert Allegretto em Dó menor D915, c.29-38.

Parte a' - reconstrução da Antecedente e Consequente.

Antecedente em Dó Maior (a')

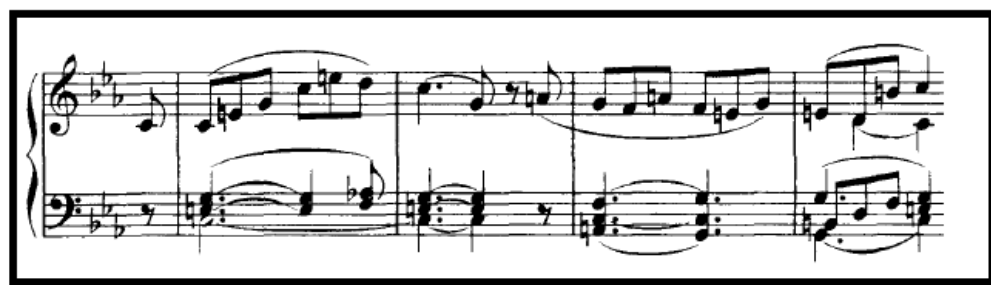

Consequente em Dó menor (a')

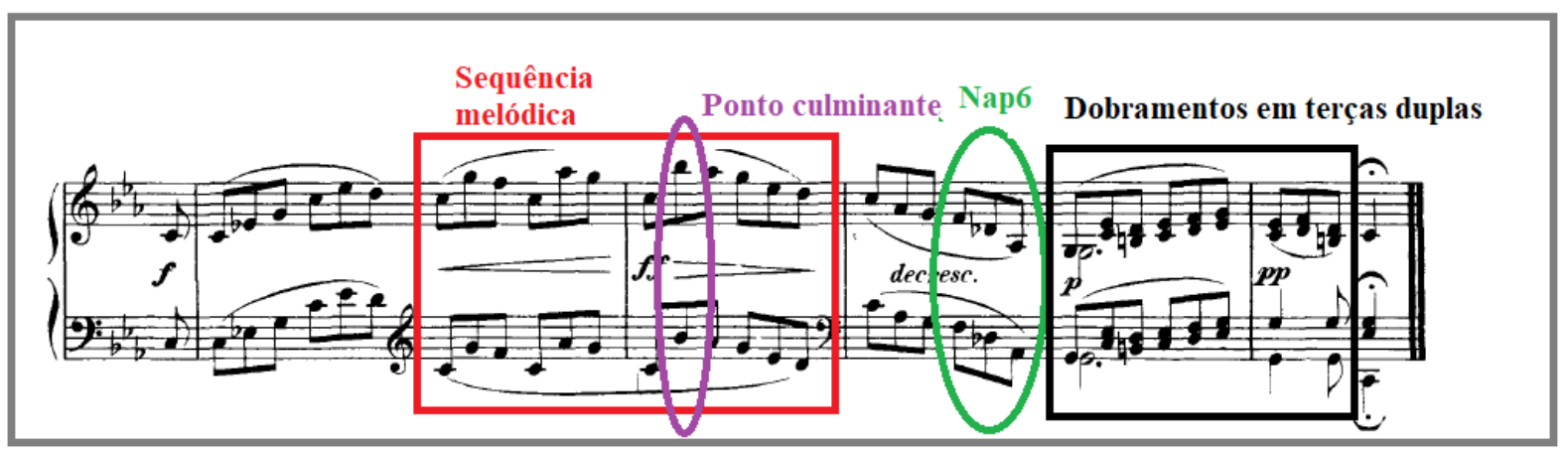

Uma das principais características desta pequena forma que pode ser definida como monotemática é a sua flexibilidade harmônica. A ideia única (o Tema) é apresentada em Dó menor, $\mathrm{Mi}^{\mathrm{b}}$ Maior, elaborada por inversão sobre a harmonia da Dominante de Dó menor na parte central para, por fim, reestabelecer-se em sua forma original em a', respectivamente, em Dó Maior e Dó menor. Trata-se de um rico material de investigação para comparação de algumas interpretações deste trecho, principalmente partindo da concepção de que a trajetória destas modulaçôes busca articular uma narrativa imbuindo as tonalidades de diferentes sentidos e graus de tensão, estes, passíveis e pertinentes de serem destacados por meio de um dos mais relevantes recursos, como afirmaram os autores, a flutuação rítmica, a agógica, o Rubato, em suma - a manipulação temporal.

Em virtude da monotematicidade da seção A do Allegretto D915 de Schubert, a utilização de duas regiões contrastantes à Tônica é, de fato, um dos principais eventos, explorando o Tema não só 
em três diferentes centros tonais, mas, sobretudo, sob três distintas perspectivas emocionais. Evidentemente, os interpretes estavam cientes disso e, através de suas interpretações, propuseram difrentes respostas a esta questão: valorizar de forma distinta cada diferente perspectiva em que o Tema foi apresentado. A manipulação temporal, neste contexto, é uma das mais evidentes repsostas a este problema interpretativo, e os dados extraídos das análises das gravaçốes corroboram que todos, de uma forma ou de outra - justamente o que defino como as suas estratégias -, buscaram enfrentá-lo.

\section{Método}

Para obter os dados requisitados nesta pesquisa, extrai, através do software Audacity $2.0^{10}$, os trechos de cada registro de áudio correspondentes aos compassos 1 a 4, 5 a 8 e 29 a 32. Estes são os compassos onde o tema principal (frase Antecedente de a) se apresenta nas tonalidades, respectivamente de Dó menor (Tônica); Mib Maior (Relativo); e Dó Maior (Homônimo). Essas tonalidades são as três regiôes utilizadas por Schubert na parte a desta forma ternária que é o Allegretto D915. Igualmente, extraí, com o mesmo software, os trechos de cada registro de áudio correspondentes aos compassos 1 a 2, 5 a 6 e 29 a 30, estes correspondentes às propostas nas mesmas tonalidades dos segmentos de quatro compassos.

O software Audacity permite visualizar a representação do formato da onda em sua localização temporal, permitindo uma precisa medição do momento exato do ataque.

A figura 04 ilustra a interface do software com a visualização da representação da onda:

\footnotetext{
${ }^{10}$ A opção por este software para a extração e análise dos extratos, ao invés do mais comum Sonic Visualiser se deu pela praticidade de extração e edição. Uma vez que a coleta de dados requerida no contexto deste trabalho, não demanda uma análise mais aprofundada do formato de onda, espectro sonoro ou outros parâmetros, e tão somente, a duração dos extratos, o software Audacity 2.0 mostra-se suficiente, atendendo plenamente às necessidades, pois ele é capaz de informar a duração de cada extrato com precisão e aproximação maior do que a empregada nos cálculos.
} 
FIGURA 04 - Interface do software Audacity -a representação da onda de todo o registro do segmento dos c.1-4 na gravação de Claudio Arrau, abaixo o detalhamento em zoom do momento exato do início da onda.
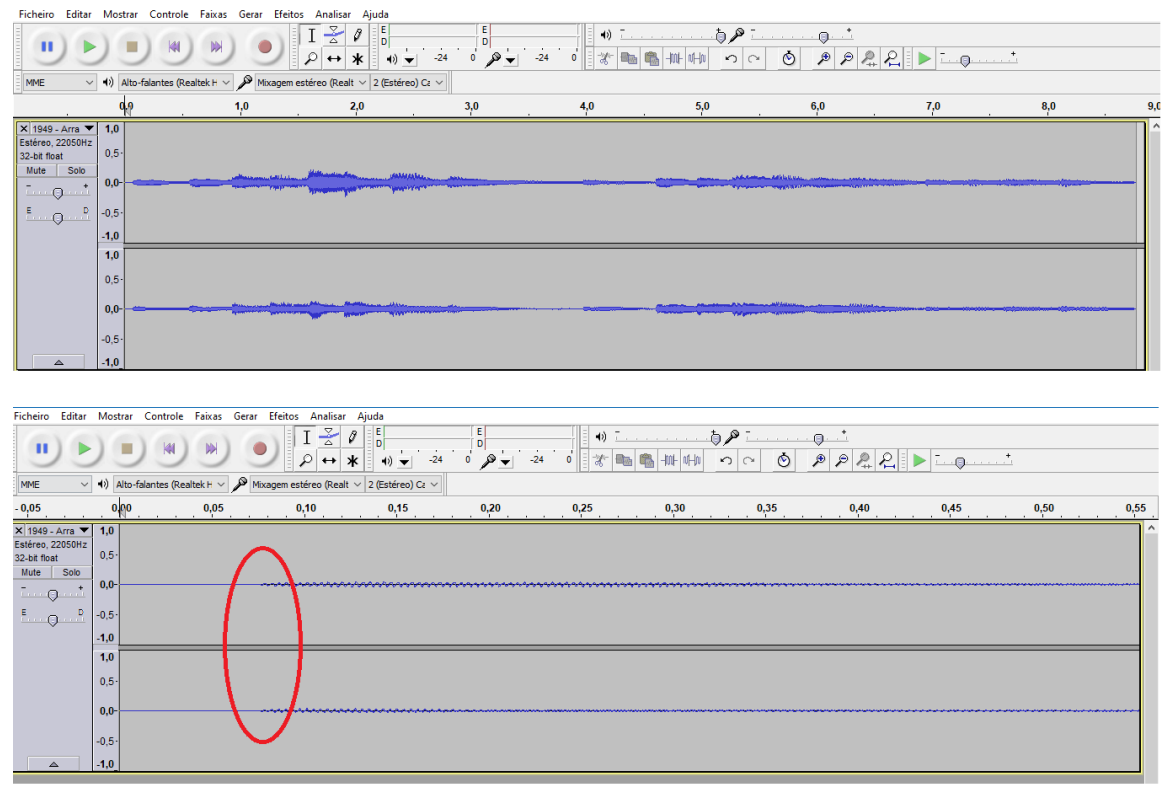

Para a extração dos trechos das gravações selecionadas estabeleci as seguintes diretrizes:

a) Para o corte, a partir do ponto inicial, foi eliminado o silêncio que antecede a faixa, sendo o momento inicial do contador sincronizado com o início da onda visível na interface do software. Dessa forma, a contagem em segundos e seus décimos correspondem ao tempo efetivo de execução em cada faixa do primeiro ao último ataque contabilizado;

b) Para o corte final, convencionei o exato início da onda correspondente à última nota contabilizada. No caso dos trechos com quatro compassos de duração, esta nota é o segundo tempo do último compasso, pois, dessa forma, variaçóes agógicas impostas a este último ataque não são contabilizadas, permitindo uma maior precisão na medição das duraçóes e andamento dos extratos, posto que muitos intérpretes sustentam o último ataque chegando, frequentemente, a executar uma fermata sobre ele ${ }^{11}$.

Para medição e cálculo dos andamentos estabeleci a seguinte norma:

\footnotetext{
${ }^{11}$ Que está literalmente presente na notação pontuando a Consequente de a.
} 
Trechos de quatro compassos têm uma duração de vinte e duas colcheias e os de dois compassos dez colcheias, conforme ilustra a figura 05. Logo, a fórmula para o cálculo do andamento em duas etapas:

i) Cálculo da duração de cada colcheia e da semínima pontuada: ((duração do extrato em segundos/quantidade de colcheias na duração selecionada)*3);

ii) Cálculo do Andamento: (60/duração da Semínima pontuda).

Como resultado da segunda etapa, tem-se o valor correspondente a quantidade de semínimas por minuto, ou seja, a indicação metronômica. Está é arredondada para o número inteiro mais próximo, obtendo, assim, o andamento médio do trecho.

FIGURA 05 - Schubert, Allegretto em Dó menor D915, c.1-4. Segmentos maior e menor de, respectivamente, vinte e duas e dez colcheias extraídos da Antecedente de a

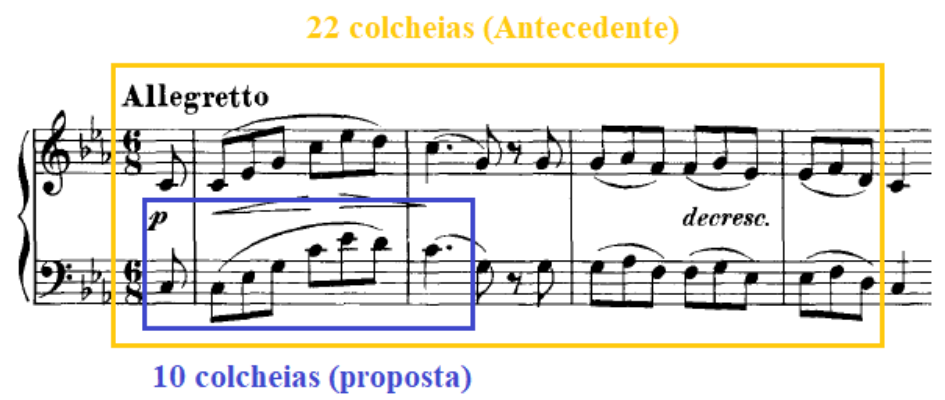

Ainda que esta medição não seja absolutamente precisa, sua margem de erro encontra-se abaixo dos $5 \%$, posto que, dentro desta faixa, fica muito evidente a presença auditiva ou não do som até o qual se realizou a medição. É dentro dessa margem de erro que interpreto, neste trabalho, a leitura dos dados.

O valor exato da margem de erro para cada faixa metronômica também pode ser deduzido pelo cálculo da diferença entre cada indicação. Esclareço aqui, que essas indicações derivam do antigo metrônomo analógico que apresentava razoável precisão no que diz respeito a diferenciação de tempos, ou seja, entre uma determinada faixa metronômica. Eis o motivo pelo qual o emprego como parâmetro para este cálculo. A tabela 03 e o gráfico 01 ilustram a variação desta margem de erro correspondente a cada faixa: 
TABELA 03 - margem de erro por faixa metronômica.

\begin{tabular}{cccccccc}
\hline Tempo & $\mathbf{3 8 - 4 6}$ & $\mathbf{4 6 - 5 8}$ & $\mathbf{5 8 - 6 0}$ & $\mathbf{6 0 - 6 9}$ & $\mathbf{6 9 - 7 2}$ & $\mathbf{7 2 - 9 2}$ & $\mathbf{9 2 - 1 0 0}$ \\
Margem de erro em \% & $5 \%$ & $4 \%$ & $3 \%$ & $5 \%$ & $4 \%$ & $5 \%$ & $4 \%$ \\
\hline
\end{tabular}

GRÁFICO 01 - margem de erro por faixa metronômica.

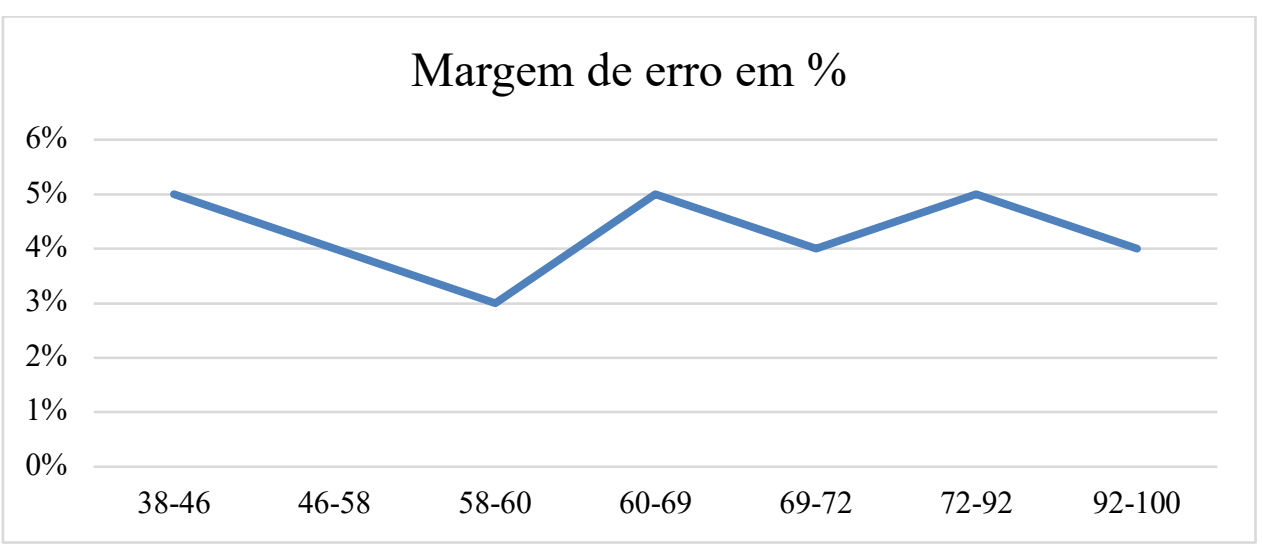

O resultado, enquanto indicação metronômica (valor), obviamente, pela flexibilidade imposta pelos intérpretes em seus registros, corresponde ao valor médio do extrato. Isso implica em estar ciente que há sutis flutuações internas de tempo. Buscando uma maior precisão nesta aferição, duas providencias foram tomadas: a primeira, já mencionada, diz respeito a remover do extrato a duração da nota final (indubitavelmente, por ser o fim de uma frase, quiçá, uma estrutura) extraindo-a do cálculo; a segunda, trata de averiguar se os dois primeiros compassos (os que compõem o que Schoenberg define como "frase" ${ }^{12}$ ), em cada situação tonal (Dó menor, Mi ${ }^{\mathrm{b}}$ Maior e Dó Maior) são apresentados com os mesmos andamentos ou se há variações significativas.

$\mathrm{Na}$ primeira situação, onde as propostas são apresentadas no mesmo andamento (consequentemente, têm a mesma ${ }^{13}$ ou muito próxima duração), uma duração distinta entre os extratos de tamanho idêntico só poderia ser justificada por uma aceleração ou retenção do

\footnotetext{
${ }^{12}$ Schoenberg, (na tradução de Eduardo Seicman) define frase como a menor unidade estrutural, uma espécie de molécula musical constituída por algumas ocorrências musicais unificadas, dotada de uma certa completude e bem adaptável à combinação com outras unidades similares. O termo frase significa, do ponto de vista da estrutura, uma unidade aproximada àquilo que se pode cantar em um só fôlego. Seu final sugere uma forma de pontuação, tal como uma vírgula. Alguns elementos, frequentemente aparecem mais de uma vez no âmbito de uma frase.

${ }^{13}$ Essa situação é rara. Apenas consta aqui como referência, não obstante, nas gravações analisadas há casos notáveis onde alguns intérpretes apresentam uma impressionante consistência de andamentos.
} 
andamento nos compassos restantes. Em outras palavras, a maior flexibilidade de andamento seria resultante de uma manipulação agógica mais proeminente na estrutura cadencial ${ }^{14}$, algo absolutamente natural na tradição de performance deste repertório ${ }^{15}$. O segundo caso é autoexplicativo, e, quase que invariavelmente impacta nas duraçóes, resultando em tamanhos significativamente distintos dos extratos de quatro compassos, ao qual os grupos em tela são extraídos.

Destarte, há as seguintes possibilidades para se abordar os trechos em questão:

a) Mantém-se os mesmos andamentos (evidentemente desprezando-se variaçóes mínimas) em todas as tonalidades;

b) Altera-se o andamento, buscando realçar a relação entre a estrutura formal da obra e a tonalidade, o que implica em subdivisões desta abordagem:

De modo a representar essas abordagens demonstro-as visualmente através de cores e gráficos onde uma linha descreve o fluxo de andamentos para cada evento. Após essa ilustração, organizo essas estratégias em abordagens, indagando se há relações visíveis e comprováveis entre si dentro das limitações deste trabalho.

\section{Discussão}

Os dados coletados após o exame dos segmentos permitiram identificar seis estratégias interpretativas no que tange a manipulação temporal. Denomino, aqui, cada estratégia por uma cor (a escolha é arbitrária), visando ilustrá-las melhor nos exemplos e gráficos. Estas estratégias são as empregadas pelos intérpretes para a apresentação da proposta em cada tonalidade (c.1-2 - Dó menor; 5-6 - Mi ${ }^{\mathrm{b}}$ Maior; e 29-30 - Dó Maior).

A tabela 04 estabelece a correspondência entre a estratégia e a cor ordenando-as por ocorrência do maior para o menor:

\footnotetext{
${ }^{14}$ No caso do Allegretto D915, esta estrutura cadencial se apresenta nos compassos 3-4; 7-8 e 31-32.

${ }^{15} \mathrm{O}$ que é ainda mais esperado após a consequente em $\mathrm{Mi}^{\mathrm{b}}$ Maior dos compassos 5-8, uma vez que ela encerra a parte a da pequena forma ternária local.
} 
TABELA 04 - correspondência entre cor e estratégia

\begin{tabular}{|c|c|c|}
\hline Cor & Ocorrências & Estratégia \\
\hline Vermelho & 11 & $\begin{array}{l}\text { O tempo em Dó menor é mais rápido que o tempo em } \mathrm{Mi}^{\mathrm{b}} \text { Maior e Dó Maior; Mi } \mathrm{i}^{\mathrm{b}} \text { Maior } \\
\text { e Dó Maior têm tempos similares. No gráfico cartesiano, é representado por uma reta } \\
\text { decrescente }(\mathrm{m}<0) \text { seguida de uma reta paralela ao eixo das abscissas }\left(\mathrm{m}^{16}=0^{17}\right) \text {. }\end{array}$ \\
\hline Amarelo & 7 & $\begin{array}{l}\text { Os três tempos são similares. No gráfico cartesiano, equivale a uma linha reta constante, } \\
\qquad \mathrm{m}=0 .\end{array}$ \\
\hline Verde & 4 & $\begin{array}{l}\text { O tempo em Dó menor é mais rápido que o tempo em } \mathrm{Mi}^{\mathrm{b}} \text { Maior, que, por sua vez, é mais } \\
\text { rápido que o tempo em Dó Maior. No gráfico cartesiano, equivale a uma linha reta } \\
\text { decrescente, } \mathrm{m}<0 .\end{array}$ \\
\hline Azul & 3 & $\begin{array}{c}\text { O tempo em Dó menor é similar ao tempo em Mi } \mathrm{i}^{\mathrm{b}} \text { Maior e ambos são mais rápidos que o } \\
\text { tempo em Dó Maior. No gráfico cartesiano, equivale a uma reta paralela ao eixo das } \\
\text { abscissas }(\mathrm{m}=0) \text { seguida de uma reta decrescente }(\mathrm{m}<0) \text {. }\end{array}$ \\
\hline Rosa & 2 & $\begin{array}{c}\text { O tempo em Dó menor é similar ao tempo em Mi } \mathrm{i}^{\mathrm{b}} \text { Maior, e, ambos são mais lentos que o } \\
\text { tempo em Dó Maior. No gráfico cartesiano, equivale a uma reta paralela ao eixo das } \\
\text { abscissas }(\mathrm{m}=0) \text { seguida de uma reta crescente }(\mathrm{m}>0)\end{array}$ \\
\hline Roxo & 2 & $\begin{array}{l}\text { O tempo em Dó menor é similar ao tempo em Dó Maior e/ou ambos são mais rápidos que } \\
\text { o tempo em Mi }{ }^{b} \text { Maior. No gráfico cartesiano, equivale a uma reta decrescente }(\mathrm{m}<0) \\
\text { seguida de uma reta crescente }(\mathrm{m}>0) .\end{array}$ \\
\hline $\begin{array}{l}\text { Caso } \\
\text { limítrofe }\end{array}$ & 1 & Entre Amarelo e Vermelho \\
\hline
\end{tabular}

Com este resultado conclui-se que, além da predominância das estratégias vermelha (36,7\% das ocorrências) e amarela (23,3\%das ocorrências) ${ }^{18}$, algumas estratégias não foram, ao todo, observadas. Se, de fato ocorrem casos em que o trecho em Dó Maior é executado mais rapidamente do que em Dó menor, não se verificou nenhum caso em que a estratégia de executar $\mathrm{Mi}^{\mathrm{b}}$ Maior e Dó Maior no mesmo andamento, porém, ambos mais rápidos que Dó menor, ocorreu.

A estratégia Rosa, empregada somente por Ray Lev (1947) e Alexander Lonquich (2001) é a única em que a Antecedente em Dó Maior é apresentada em andamento mais rápido que a em Dó Menor. Em todas as outras estratégias estas apresentaçóes ou são similares ou têm na em Dó Maior um andamento menos movido.

Os gráficos 02 a 07 permitem visualizar cada uma destas estratégias projetadas no plano

\footnotetext{
${ }^{16} \mathrm{M}$ é o coeficiente angular da equação reduzida da reta. Quando $\mathrm{m}=0$ representa uma reta paralela ao eixo $\mathrm{x}$ (abscissas); quando $\mathrm{m}>0$ a reta é crescente; e, quando $\mathrm{m}<0$ a reta é decrescente. Essa representação é a ideal, sendo que, considera-se a estratégia a proximidade de seu gráfico real com este modelo.

${ }^{17}$ Mesmo em casos em que $\mathrm{m}=0$ pode se ter uma pequena inflexão no gráfico, sendo ele formado por duas retas. Isso se dá em virtude da margem de erro e pelos critérios de aproximação já definidos na metodologia. Assim sendo, entende-se que para todo $\mathrm{m}=0$ é preciso verificar a tendência da reta.

${ }^{18}$ Juntas correspondem à aproximadamente $60 \%$ do total.
} 
cartesiano $^{19}$, destacando os intérpretes que as empregam ${ }^{20}$. Com esta representação gráfica, é possível vislumbrar com maior clareza as proporçôes entre os tempi dentro de cada estratégia.

\section{GRÁFICO 02 - Estratégia Vermelha ${ }^{21}$}

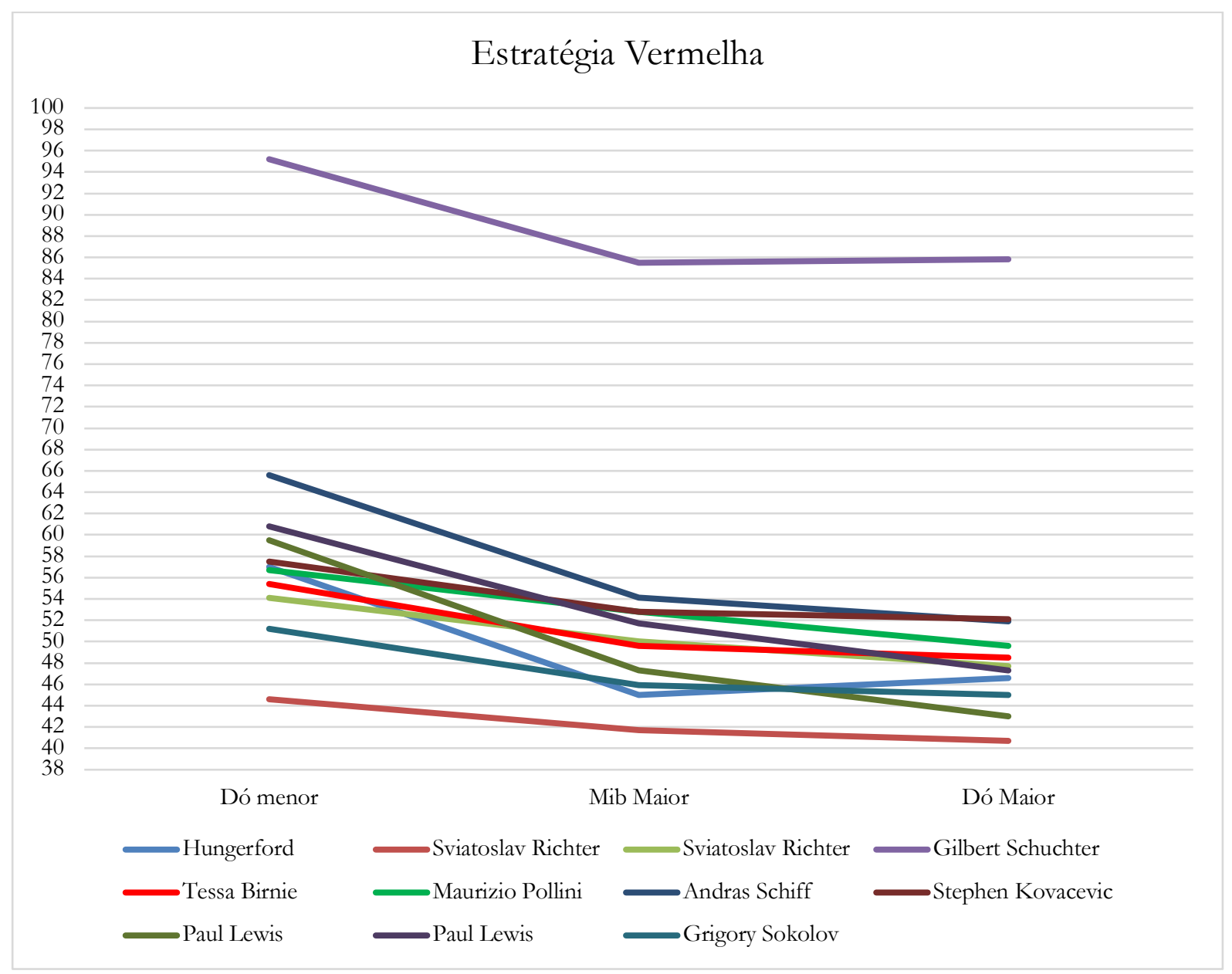

${ }^{19}$ De forma a padronizar os gráficos e proporcionar uma visão proporcional, eles foram configurados para ter em sua escala principal (eixo y) valor máximo de 100 e mínimo de 38 - representando, respectivamente, os valores mais próximos a maior e a menor indicação metronômica encontrada nos dados. As unidades de representação ocorrem a cada dois pontos, independentemente da progressão metronômica de cada faixa, fornecendo a visão proporcional e topográfica dos tempi. No eixo $\mathrm{x}$, foram fixados três pontos referentes às apresentações das Antecedentes nas tonalidades investigadas.

${ }^{20}$ No apêndice deste trabalho encontra-se uma tabela com o detalhamento dos tempi para cada registro.

${ }^{21}$ Aparentemente, o gráfico de Bruce Hungerford se opõe a estratégia. Esclareço que o leve incremento representado pela linha crescente após o ponto $\mathrm{Mi}^{\mathrm{b}}$ Maior está dentro da margem de erro da faixa metronômica, conforme os critérios estabelecidos na metodologia. A diferença entre o ponto $\mathrm{Mi}^{\mathrm{b}}$ Maior e o ponto Dó Maior é dos tempi 45 e 47 respectivamente, significando um incremento de $4,4 \%$, exato valor para esta faixa. 
HARTMANN, Ernesto. Estratégias de manipulação temporal no “Allegretto em Dó Menor D915” de Franz Schubert. Revista Vórtex, Curitiba, v.9, n.1, p. 1-41, 2021.

GRÁFICO 03- Estratégia Amarela- em pontilhado a linha de tendência desta estratégia representada por uma reta com coeficiente angular $\mathrm{m}$ tendendo a 0 .

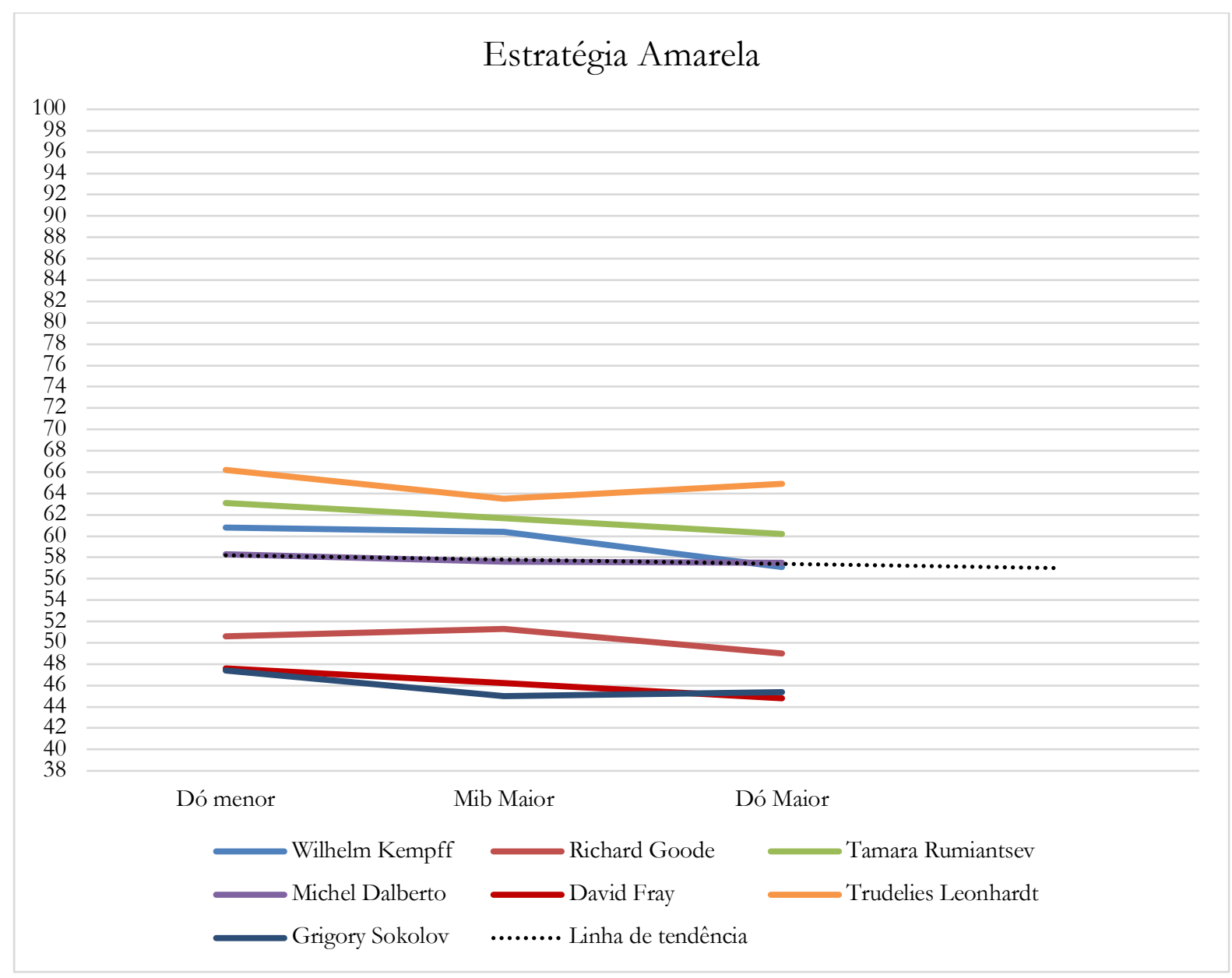


HARTMANN, Ernesto. Estratégias de manipulação temporal no “Allegretto em Dó Menor D915” de Franz Schubert. Revista Vórtex, Curitiba, v.9, n.1, p. 1-41, 2021.

GRÁFICO 04 - Estratégia Verde

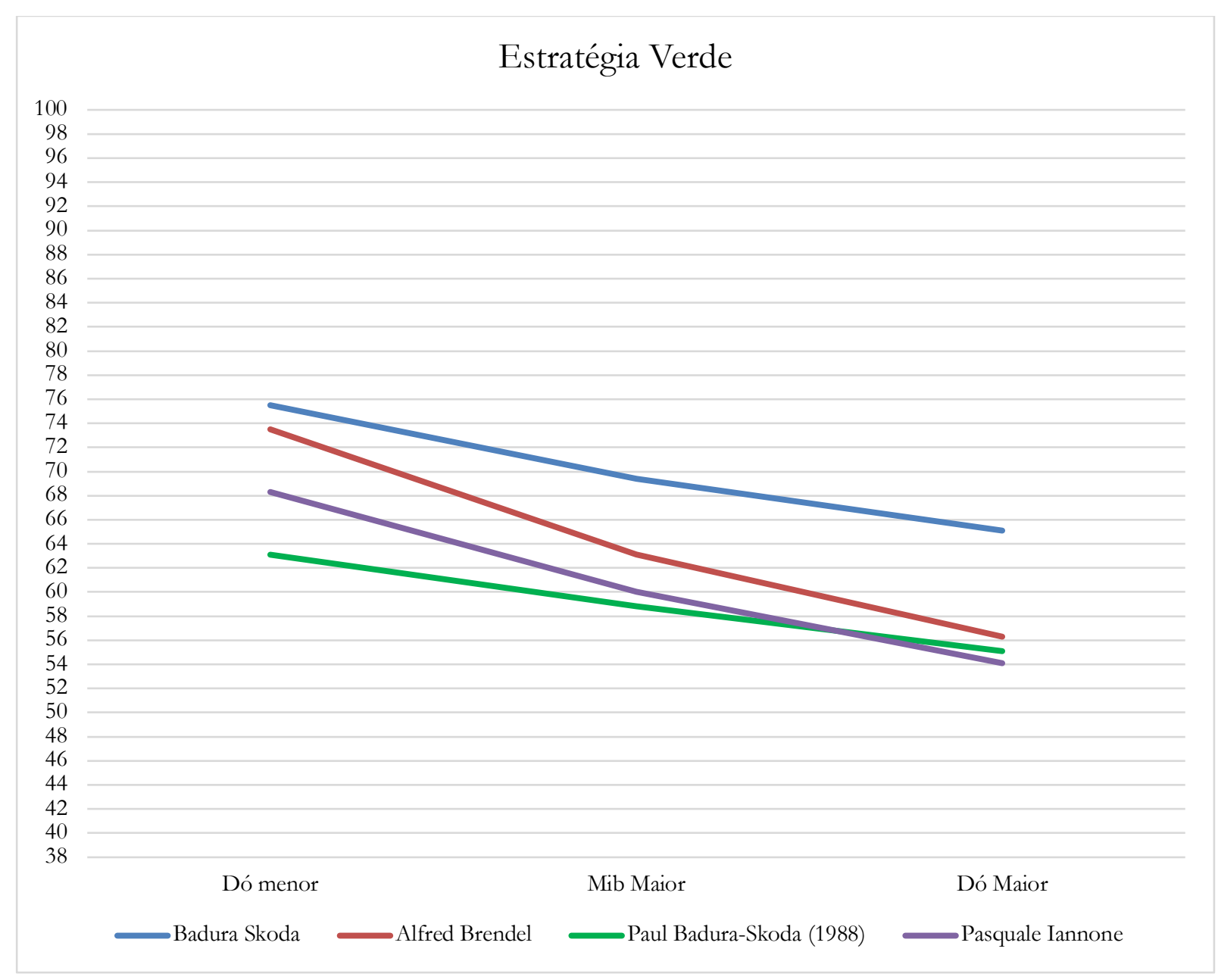


HARTMANN, Ernesto. Estratégias de manipulação temporal no “Allegretto em Dó Menor D915” de Franz Schubert. Revista Vórtex, Curitiba, v.9, n.1, p. 1-41, 2021.

GRÁFICO 05 - Estratégia Azul

\section{Estratégia Azul}

100
98
96
94
92
90
88
86
84
82
80
78
76
74
72
70
68
66
64
62
60
58
56
54
52
50
48
46
44
42
40
38

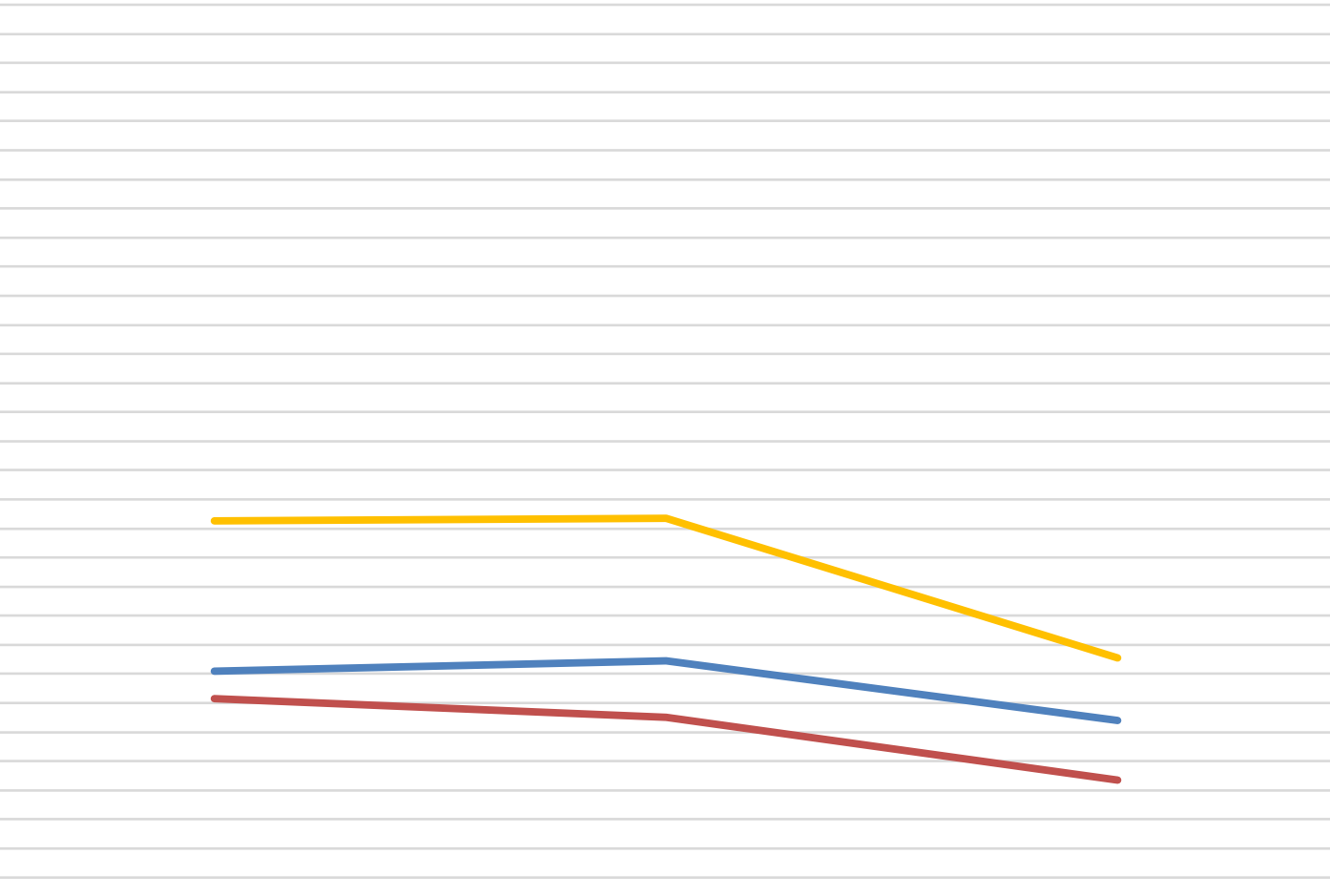

Dó menor

Mib Maior

Dó Maior

$\longrightarrow$ Arthur Schnabel $\longrightarrow$ Claudio Arrau $\longrightarrow$ Edith Vogel 
HARTMANN, Ernesto. Estratégias de manipulação temporal no “Allegretto em Dó Menor D915” de Franz Schubert. Revista Vórtex, Curitiba, v.9, n.1, p. 1-41, 2021.

\section{GRÁFICO 06 - Estratégia Rosa}

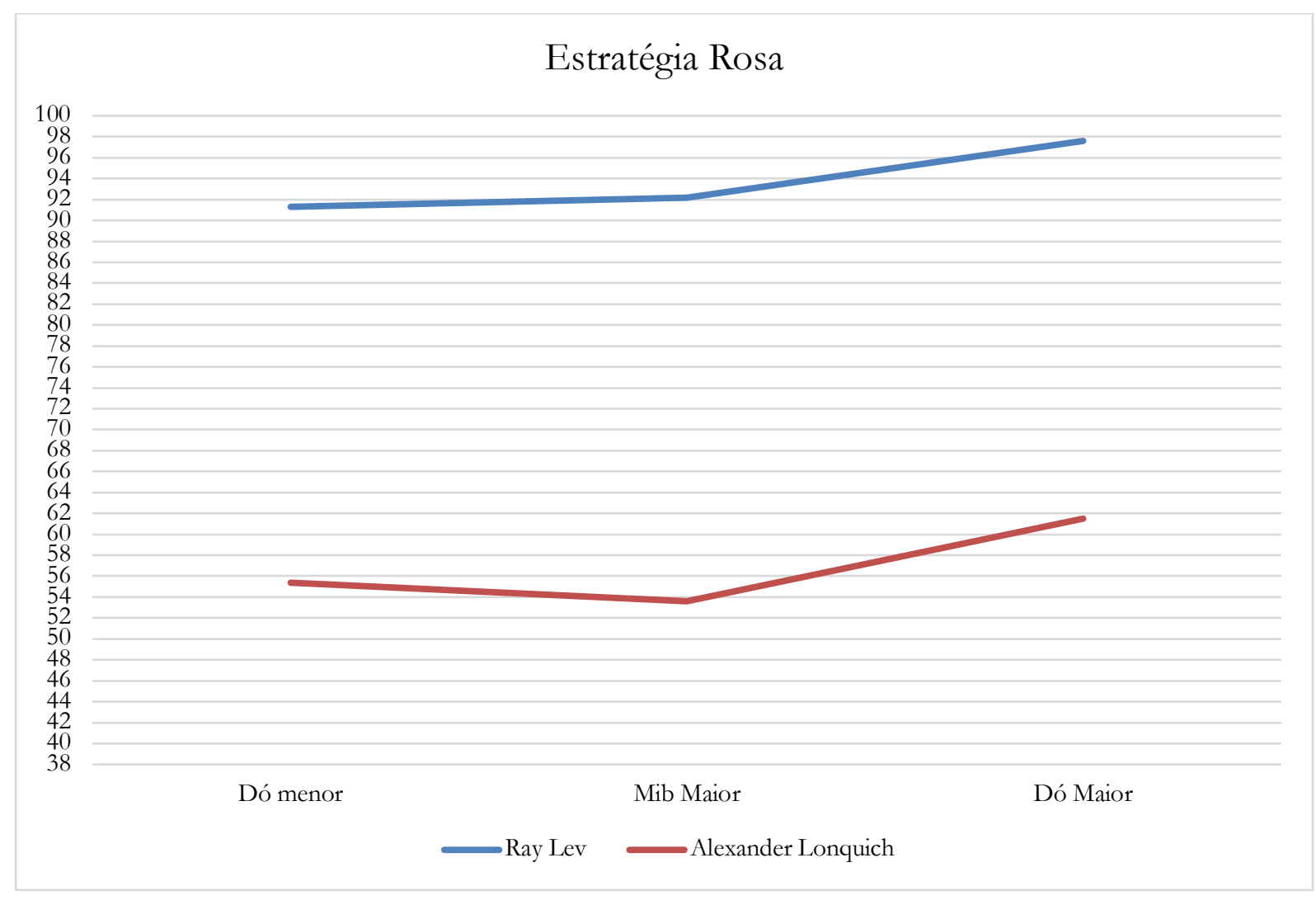




\section{GRÁFICO 07 - Estratégia Roxo}

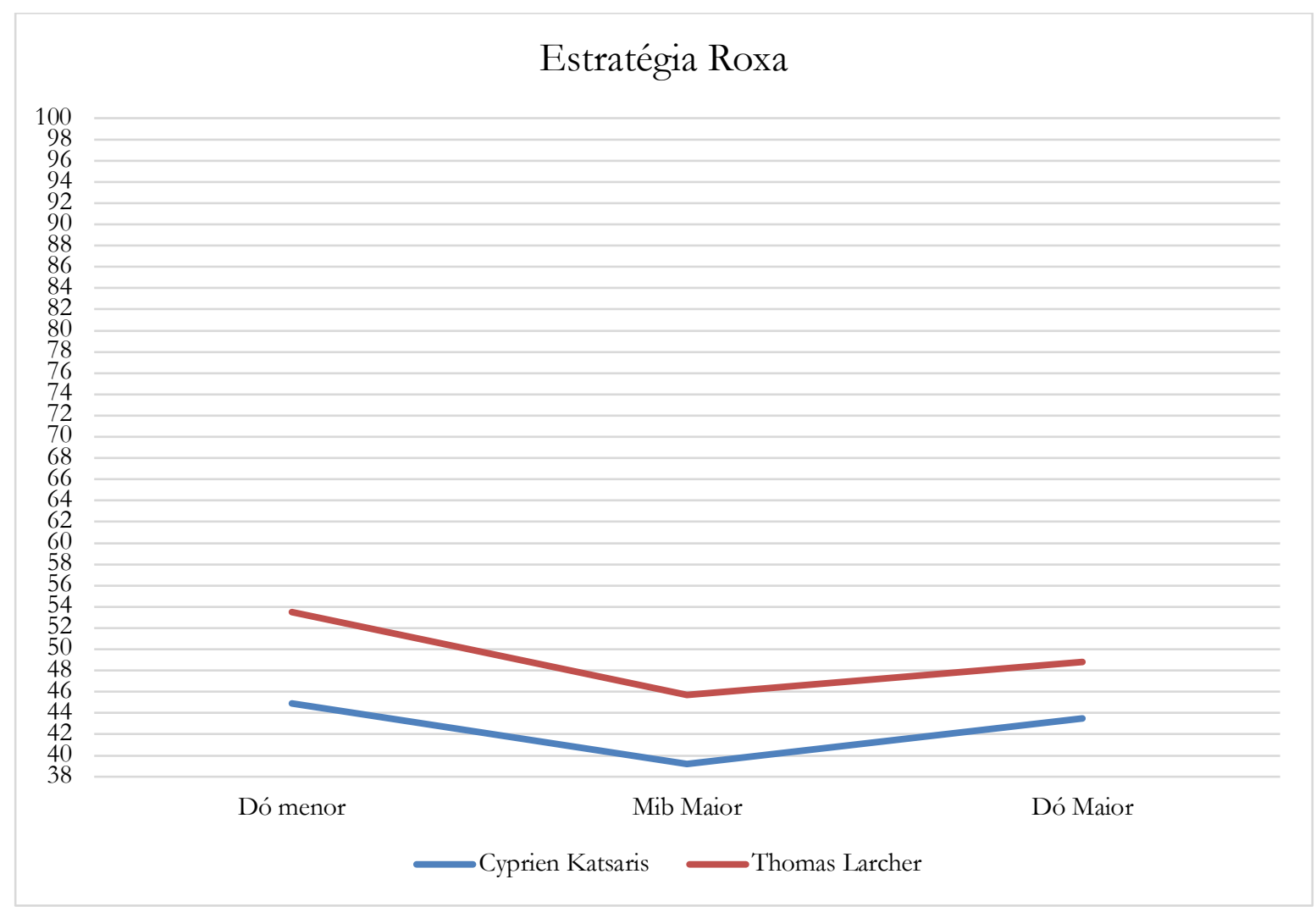

\section{Caso limítrofe}

O registro da pianista portuguesa Maria João Pires (1998) mostrou-se um caso limítrofe que merece aprofundamento no que diz respeito a sua classificação. Os tempi realizados pela pianista são, respectivamente, para os compassos 1-2; 5-6 e 29-30: 62; 59 e 58 bpm. De fato, são tempi muito próximos que representam decréscimos de 5,1\% e 1,8\%. Estes valores apontam uma similaridade dentro da margem de erro entre o segundo e terceiro tempi. Contudo, o primeiro decréscimo está apenas $0,1 \%$ fora da margem de erro, acrescido de que a sensação geral, ao escutar o registro, é de que Pires mantém o andamento constante (em virtude da manipulação de outros parâmetros em jogo como, por exemplo, a dinâmica ${ }^{22}$ ). Por isso, decidi alocar a estratégia adotada por ela como limítrofe entre as amarela e vermelha. Contudo, ao compará-la com as estratégias para um segmento maior (como será feito adiante neste trabalho) ela será categorizada como amarela.

\footnotetext{
${ }^{22}$ Cuja análise está fora do escopo deste trabalho.
} 


\section{Comparando as estratégias dos segmentos da Antecedente e da Proposta}

A tabela 05 estabelece a comparação entre as estratégias adotadas pelos intérpretes nos dois segmentos de registros analisados. Os de 4 compassos (que inclui a integra da frase antecedente) e o de 2 compassos (somente a proposta desta Antecedente). As cores correspondem às estratégias empregadas conforme anteriormente definido.

TABELA 05 - Estratégias comparadas nos registros entre o segmento de quatro e dois compassos. Em destaque cinza as interpretações que mantém a mesma estratégia nos dois segmentos.

\begin{tabular}{|c|c|c|c|c|c|c|c|}
\hline Ano & Artista & 4 & 2 & Ano & Artista & 4 & 2 \\
\hline 1939 & Arthur Schnabel & & & 1990 & Andras Schiff & & \\
\hline 1947 & Ray Lev & & & 1994 & Pasquale Iannone & & \\
\hline 1949 & Claudio Arrau & & & 1995 & S. Kovacevic & & \\
\hline 1956 & Badura Skoda & & & 1996 & Cyprien Katsaris & & \\
\hline 1957 (circa) & Bruce Hungerford & & & 1998 & Maria João Pires ${ }^{23}$ & & \\
\hline 1961 & Sviatoslav Richter & & & 1999 & T. Larcher & & \\
\hline 1963 & Sviatoslav Richter & & & 2000 & T.Rumiantsev & & \\
\hline 1967 & Wilhelm Kempff & & & 2001 & A. Lonquich & & \\
\hline $1968-1970$ & Gilbert Schuchter & & & 2005 & Michel Dalberto & & \\
\hline 1978 & Edith Vogel & & & 2009 & David Fray & & \\
\hline 1982 & Tessa Birnie & & & 2010 & T. Leonhardt & & \\
\hline 1985 & Richard Goode & & & 2011 & Paul Lewis & & \\
\hline 1987 & Maurizio Pollini & & & 2013 & Paul Lewis & & \\
\hline 1988 & Alfred Brendel & & & 2018 & Grigory Sokolov & & \\
\hline 1988 & Paul Badura-Skoda & & & 2019 & Grigory Sokolov & & \\
\hline
\end{tabular}

Como pode ser observado, dezessete interpretações mantém a estratégia tanto para o maior segmento como para o menor, ou seja, mesmo que haja manipulação temporal nas estruturas cadenciais, o conceito inerente à estratégia já se manifesta na escolha dos tempi para a proposta em cada tonalidade. Tratarei, a seguir, dos casos em que as estratégias são distintas entre os segmentos.

\footnotetext{
${ }^{23}$ Aqui, em virtude do já exposto, categorizado como estratégia amarelo.
} 
TABELA 05a - Arthur Schnabel

\begin{tabular}{llcccccc}
\hline Ano & Artista & c.1-4 & c.5-8 & $\mathbf{2 9 - 3 2}$ & c.1-2 & c.5-6 & c.29-30 \\
1939 & Schnabel & 56 & 52 & 53 & 52 & 53 & 49 \\
\hline
\end{tabular}

Com esta combinação, é possível perceber como Schnabel tende a acelerar ao invés de reduzir o tempo médio da estrutura cadencial. Os compassos 5-8 quando comparados aos compassos 5-6 são similares em tempo. Isso indica que as cadências da Antecedente de a em Dó menor e da Antecedente de a’ em Dó Maior têm suas propostas muito claramente demarcadas na estratégia azul, sendo, então o tempo das estruturas cadenciais acelerado.

TABELA 05b - Paul Badura Skoda

\begin{tabular}{cccccccc}
\hline Ano & Artista & c.1-4 & c.5-8 & 29-32 & c.1-2 & c.5-6 & c.29-30 \\
1956 & $\begin{array}{c}\text { Badura- } \\
\text { Skoda }\end{array}$ & 73 & 70 & 68 & 76 & 69 & 65 \\
\hline
\end{tabular}

TABELA 05c - Paul Badura Skoda

\begin{tabular}{rccccccc}
\hline Ano & Artista & c.1-4 & c.5-8 & 29-32 & c.1-2 & c.5-6 & c.29-30 \\
1988 & $\begin{array}{c}\text { Badura- } \\
\text { Skoda }\end{array}$ & 65 & 60 & 60 & 63 & 59 & 55 \\
\hline
\end{tabular}

Na combinação empregada por Paul Badura-Skoda em suas duas gravações as relaçóes entre os segmentos maiores e menores estão dentro da margem de erro, com exceção da Antecedente de a'. Isso indica que a cadência correspondente sofre uma manipulação mais proeminente, em particular, na gravação de 1988. É notável que, mesmo com tempi bem distintos entre as duas gravações (mesmo que, aproximadamente, trinta anos distante uma da outra e com instrumentos distintos) Badura-Skoda tenha usado a mesma abordagem. De fato, na gravação de 1956 a antecedente de a é a que apresenta maior diferença, sendo sua proposta sutilmente mais movida. Já na gravação de 1988 o inverso se dá com a antecedente de a' sendo sensivelmente mais lenta que o segmento total. $\mathrm{Ou}$ seja, as propostas estão claramente marcadas.

TABELA 05d - Ray Lev

\begin{tabular}{llcccccc}
\hline Ano & Artista & c.1-4 & c.5-8 & $\mathbf{2 9 - 3 2}$ & c.1-2 & c.5-6 & c.29-30 \\
1947 & Ray Lev & 94 & 90 & 98 & 91 & 92 & 98 \\
\hline
\end{tabular}


TABELA 05e - Alexander Lonquich

\begin{tabular}{lccccccc}
\hline Ano & Artista & c.1-4 & c.5-8 & 29-32 & c.1-2 & c.5-6 & c.29-30 \\
2001 & Lonquich & 57 & 51 & 58 & 55 & 54 & 62 \\
\hline
\end{tabular}

A estratégia empregada por Lev e Lonquich para os segmentos de dois compassos são distintas de todas as outras. São os dois únicos intérpretes que adotam um andamento mais movido na Antecedente de a' em comparação a de a. No caso da gravação de Lonquich, isso só é possível de ser visualizado ao se separar os segmentos. Os tempi 58 e 57 (c.1-4; c.29-58) são tão próximos que estão confortavelmente dentro da margem erro. Contudo, na segmentação que explicita a proposta das frases, percebe-se que o tempo em a é similar, porém, claramente mais lento que em a’. a principal manipulação do tempo na cadência está, justamente, na Antecedente de a na gravação de Lev e na Antecedente de a' na de Lonquich, sendo, esta última a mais evidente.

TABELA 05f - Sviatoslav Richter 1963

\begin{tabular}{cccccccc}
\hline Ano & Artista & c.1-4 & c.5-8 & $\mathbf{2 9 - 3 2}$ & c.1-2 & c.5-6 & c.29-30 \\
1963 & Richter & 44 & 40 & 42 & 45 & 42 & 41 \\
\hline
\end{tabular}

Na gravação de 1963 de Sviatoslav Richter não se verificam alterações significativas entre as abordagens dos dois segmentos, apesar de representarem estratégias distintas. Elas estão bem próximas da margem de erro. Contudo, ao examinar o menor segmento, é possível observar um decréscimo progressivo no tempo. Dessa forma, conclui-se que a cadência da Consequente de a é o local onde Richter mais manipula o tempo, promovendo um sutil, porém, perceptível rallentando.

TABELA 05g - Richard Goode

\begin{tabular}{llcccccc}
\hline Ano & Artista & c.1-4 & c.5-8 & 29-32 & c.1-2 & c.5-6 & c.29-30 \\
1985 & Goode & 54 & 50 & 52 & 51 & 51 & 49 \\
\hline
\end{tabular}

TABELA 05h - T Leonhardt

\begin{tabular}{lccccccc}
\hline Ano & Artista & c.1-4 & c.5-8 & 29-32 & c.1-2 & c.5-6 & c.29-30 \\
2001 & Leonhardt & 68 & 62 & 68 & 66 & 64 & 65 \\
\hline
\end{tabular}

TABELA 05i - Grigory Sokolov 2018

\begin{tabular}{llcccccc}
\hline Ano & Artista & c.1-4 & c.5-8 & 29-32 & c.1-2 & c.5-6 & c.29-30 \\
2018 & Sokolov & 48 & 45 & 47 & 47 & 45 & 45 \\
\hline
\end{tabular}


Nas três gravaçóes acima as maiores variações nos tempi entre os segmentos ocorre em Goode, nas Antecedentes de a e a'; e em Leonhardt na Antecedente de a'. Como todos os tempi do segmento menor são menores do que os do segmento maior (nestes casos), conclui-se que ambos os intérpretes realizam as correspondentes estruturas cadenciais de forma mais movida. A gravação de Sokolov é onde as duas estratégias mais se aproximam, porém, no segmento de dois compassos da proposta da Antecedente de a' é onde a cadência mais interfere, posto que esta proposta está no mesmo andamento da sua equivalente na Consequente de a. Isso justifica a diferenciação em cores nestes segmentos.

TABELA 05j - Maurizio Pollini

\begin{tabular}{cccccccc}
\hline Ano & Artista & c.1-4 & c.5-8 & $\mathbf{2 9 - 3 2}$ & c.1-2 & c.5-6 & c.29-30 \\
1987 & Pollini & 58 & 53 & 49 & 57 & 53 & 50 \\
\hline
\end{tabular}

TABELA 05k - Paul Lewis 2011

\begin{tabular}{lccccccc}
\hline Ano & Artista & c.1-4 & c.5-8 & $\mathbf{2 9 - 3 2}$ & c.1-2 & c.5-6 & c.29-30 \\
2011 & Lewis & 63 & 53 & 50 & 60 & 47 & 43 \\
\hline
\end{tabular}

TABELA 051 - Paul Lewis 2013

\begin{tabular}{lccccccc}
\hline Ano & Artista & c.1-4 & c.5-8 & 29-32 & c.1-2 & c.5-6 & c.29-30 \\
2013 & Lewis & 62 & 58 & 54 & 61 & 52 & 47 \\
\hline
\end{tabular}

A gravação de Maurizio Pollini tem seus segmentos muito similares em relação ao tempo, apesar de apresentar duas estratégias distintas (em função da margem de erro). Fica evidente que as cadências não influenciam o conceito básico de uma apresentação cada vez menos movida da proposta, tal qual Paul Badura-Skoda, em suas duas gravaçôes que reproduzem as mesmas estratégias. O que valeu para Pollini, aqui, também vale para Lewis, uma vez que suas duas abordagens estão muito próximas da margem de erro, novamente justificando sua distinção. Contudo, observa-se uma diferença mais pronunciada na Consequente de a e na Antecedente de a', que, em seus segmentos maiores, têm tempi mais movidos, logo, apontando para o realce da redução do tempo da proposta nesses dois casos. 
TABELA 05m - Wilhelm Kempff

\begin{tabular}{cccccccc}
\hline Ano & Artista & c.1-4 & c.5-8 & $\mathbf{2 9 - 3 2}$ & c.1-2 & c.5-6 & c.29-30 \\
1967 & Kempff & 68 & 61 & 57 & 61 & 60 & 57 \\
\hline
\end{tabular}

Nesta gravação a diferença reside exclusivamente no segmento maior da Antecedente de a (que está em tempo mais movido que o segmento menor). Conforme o que se afirmou sobre as outras gravações, pode-se concluir, aqui, que Kempff marca mais claramente cada evento através das alteraçóes de tempo na cadência, que, em virtude da estratégia adotada, ressalta a Consequente de a e a Antecedente de a', ambas em tempi menos movidos.

\section{O andamento médio inicial e sua relação cronológica}

O andamento médio inicial (ou seja, da proposta da Antecedente de a) nas gravaçôes selecionadas varia conforme a época.

As tabelas 05/06 e os gráficos 08/09 ilustram a progressiva redução do andamento ${ }^{24}$ ao longo das décadas. Os dados limitam-se aos das gravaçôes das décadas de 1960, e 1980 a 2010, onde há pelo menos quatro gravaçôes disponíveis para uma comparação. A primeira tabela e o primeiro gráfico apresentam os resultados com o cálculo de todas as gravaçóes. A segunda tabela e o segundo gráfico o tempo médio, excluindo-se o maior e menor valor observado em cada década.

TABELA 06 - Andamentos médios ao longo das décadas

\begin{tabular}{ccc}
\hline Andamento médio inicial & Antecedente completa & Apenas a proposta \\
\hline Década de 1960 & 65 & 64 \\
Década de 1980 & 62 & 61 \\
Década de 1990 & 59 & 58 \\
Década de 2000 & 57 & 57 \\
Década de 2010 & 56 & 55 \\
\hline
\end{tabular}

\footnotetext{
${ }^{24} \mathrm{O}$ andamento médio inicial é o valor do andamento dos segmentos da Antecedente de a.
} 
GRÁFICO 08 - Andamento médio ao longo das décadas

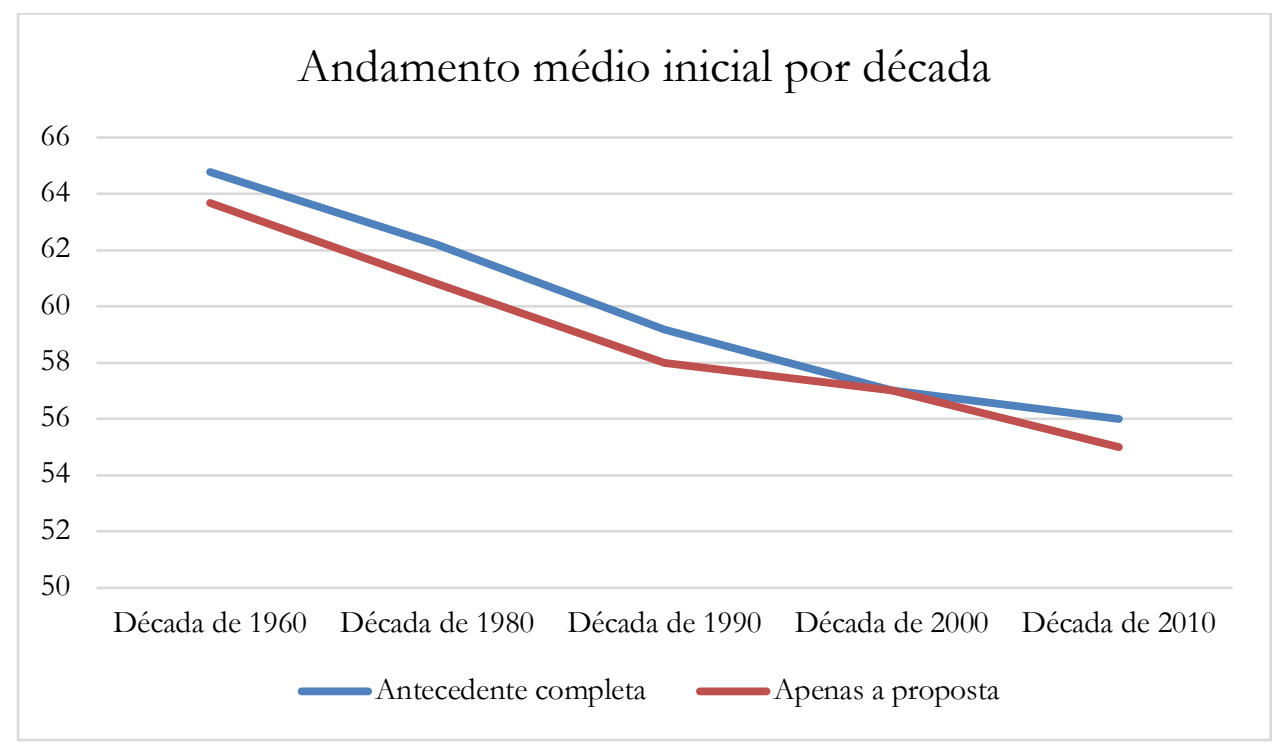

TABELA 07 - Andamento médio ao longo das décadas excluídos o maior e menor valor

\begin{tabular}{ccc}
\hline Andamento médio inicial (excluindo o maior e menor valor) & Antecedente completa & Apenas a proposta \\
\hline Década de 1960 & 61 & 58 \\
Década de 1980 & 61 & 60 \\
Década de 1990 & 60 & 58 \\
Década de 2000 & 57 & 57 \\
Década de 2010 & 57 & 56 \\
\hline
\end{tabular}

GRÁFICO 09 - Andamento médio ao longo das décadas excluídos o maior e o menor valor.

\section{Andamento médio por década (excluidos o maior e o menor valor)}

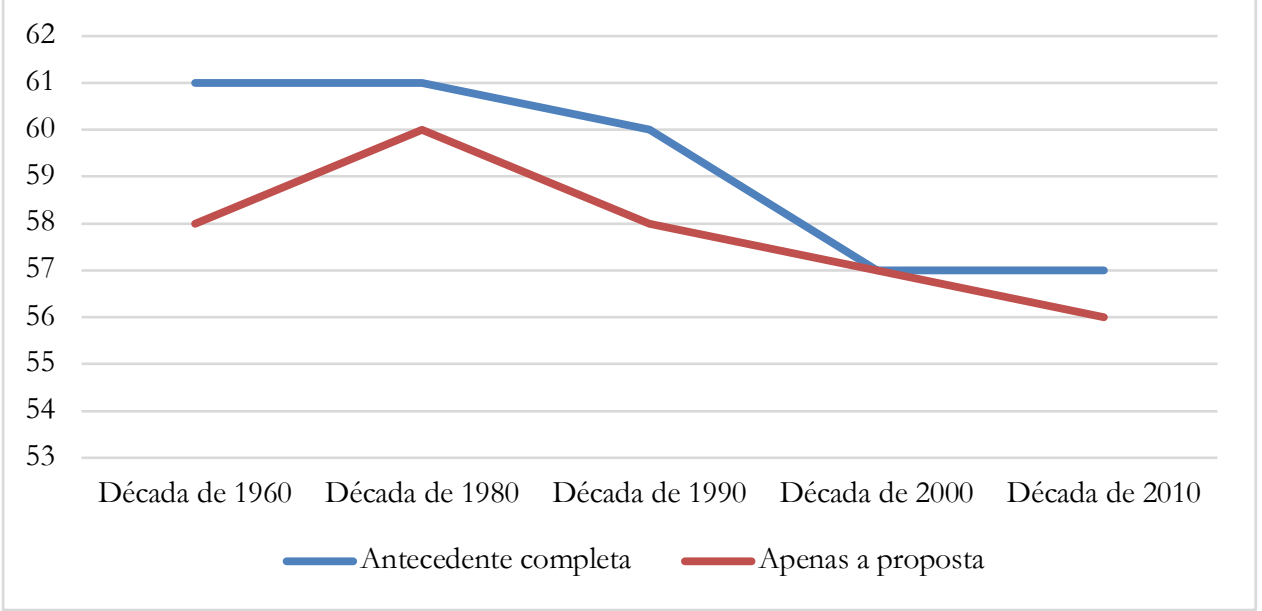


Ao visualizar os gráficos, evidencia-se uma redução progressiva do andamento ao longo do tempo, independente de qual dos dois métodos foi empregado. Pelo primeiro método a variação é de 10,3\% (64 bpm - $58 \mathrm{bpm})$ e, pelo segundo, de 5,1\% (61 bpm - $57 \mathrm{bpm})$. Ambos os valores estão acima de, ao menos uma indicação metronômica e da margem de erro para a faixa. Mesmo que discreta, trata-se de uma redução significativa. O único acréscimo visível ocorre no segundo gráfico entre as décadas de 1960 e 1980 contemplando uma variação de 3,3\%, ou seja, uma indicação metronômica (58-60) nesta faixa, muito pouco abaixo da margem de erro. Para a média da Antecedente no segundo gráfico, verifica-se uma estabilização entre as décadas de 2000 e 2010 na faixa de $57 \mathrm{bpm}$.

Em outras palavras, podemos afirmar que, para este conjunto de gravações, observa-se, em média, um nítido decréscimo do andamento médio da peça ao longo do tempo ${ }^{25}$.

\section{Estratégias por década}

As figuras 06 e 07 ilustram a distribuição de estratégias dos dois segmentos, respectivamente, ao longo das décadas. O emprego das cores nessas figuras permite uma visualização mais imediata da distribuição das estratégias:

FIGURA 06 - Distribuição das estratégias por década - Antecedente completa

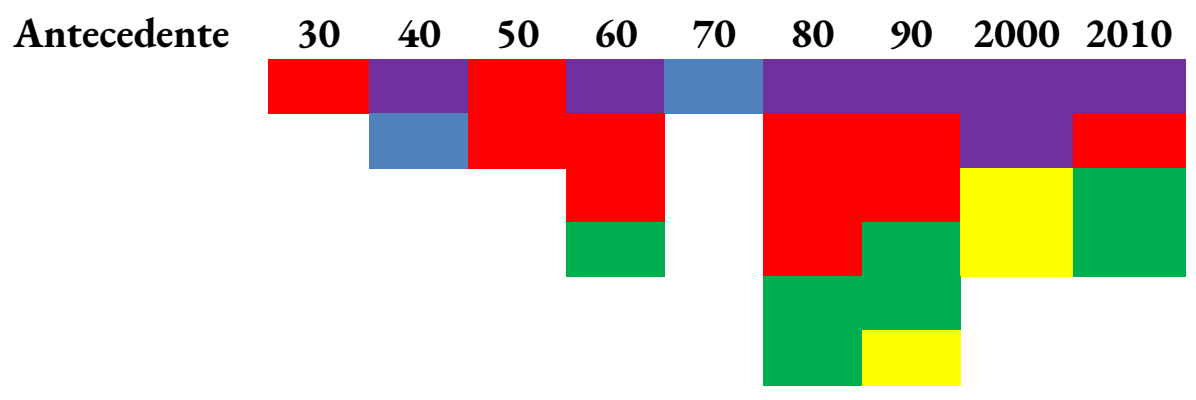

\footnotetext{
${ }^{25}$ Mesmo que ocorram inúmeras variações ao longo da peça no andamento, o estilo ao qual ela pertence estabelece uma razoável constante que se apresenta frequentemente na enunciação temática inicial.
} 
FIGURA 07 - Distribuição das estratégias por'década - Proposta

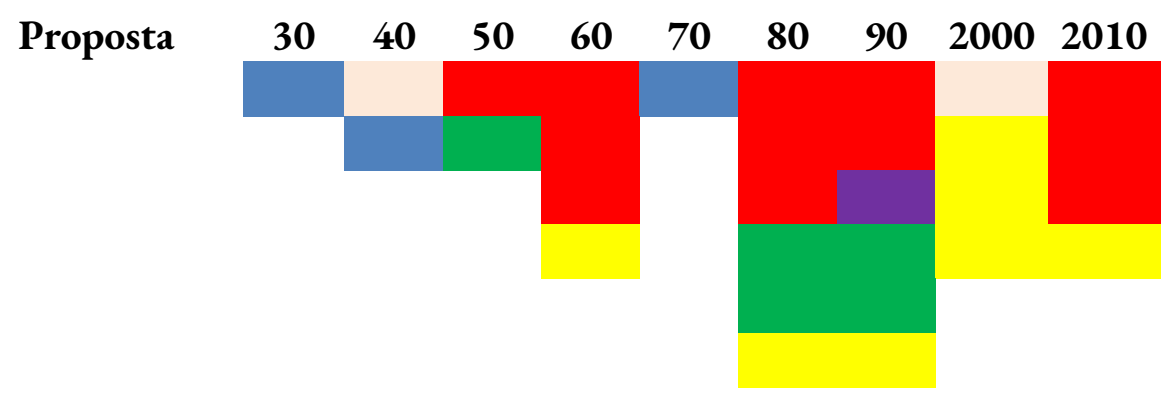

Os gráficos 10 e 11 correlacionam as estratégias nas décadas de 1960 e 1980-2010 com a suas respectivas proporções, possibilitando visualizar alguns padrões:

GRÁFICO 10 - Distribuição das estratégias por década - Antecedente

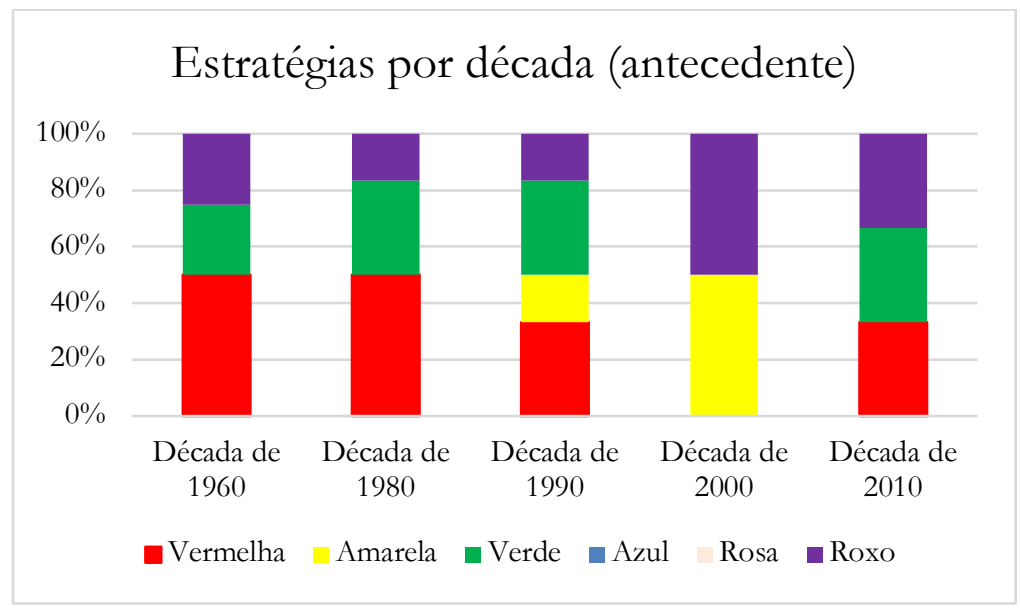

GRÁFICO 11 - Distribuição das estratégias por década - Proposta

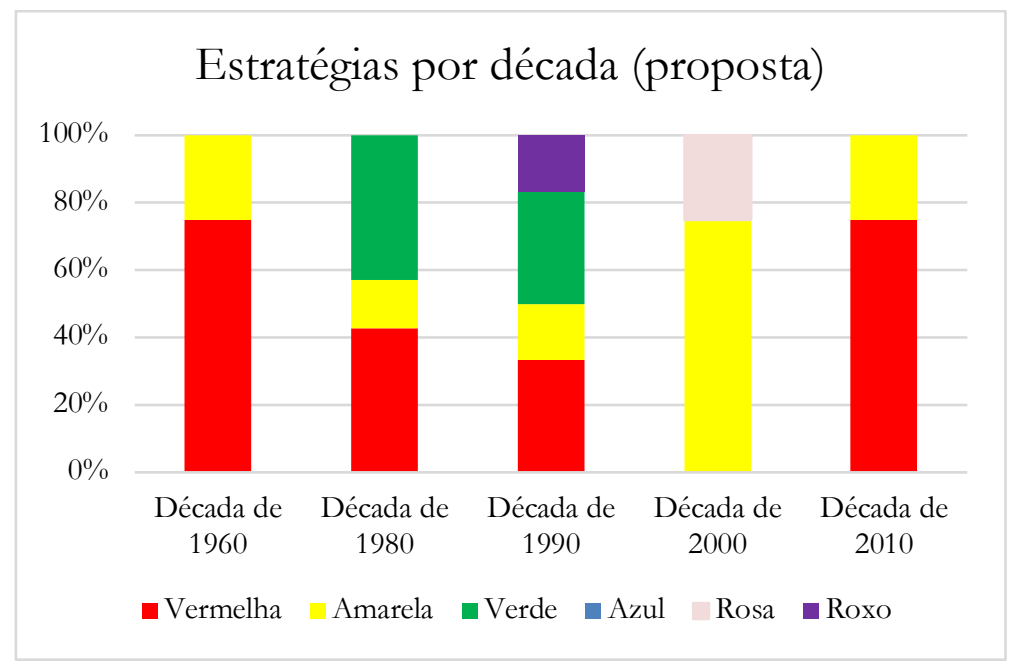


Alguns fatos são notáveis. Em nenhuma destas décadas observou-se a estratégia azul, presente nas gravações das décadas de 1930, 1940 e 1970, justamente, as que, por ausência de dados suficientes para comparação não foram consideradas.

As estratégias empregadas pelos intérpretes na década de 2010 muito se assemelham as da década de 1960 (meio século de diferença) em ambas as tabelas. Para a Antecedente, as três primeiras décadas consideradas apresentam bastante similaridade, com três estratégias - roxa, verde e vermelha, com a vermelha perdendo espaço para a amarela na década de 1990 (Maria João Pires) e uma leve expansão da verde, ocupando o espaço da roxa. Na década seguinte (2000) a abordagem amarela adquire maiores proporçóes em ambos os gráficos, sendo, inclusive majoritária como abordagem na proposta.

Neste contexto, a década de 2000 se apresenta-se como um contraponto a todas as outras, não coincidentemente, é a década da virada do século e milênio.

Ainda, ao observar a presença da estratégia roxa para a Antecedente em todas as décadas consideradas, mas em apenas uma ocorrência para a proposta, compreende-se que, em linhas gerais a Consequente ( $\mathrm{Mi}^{\mathrm{b}}$ Maior - tonalidade relativa, mas não homônima) é o local onde mais se manipula a estrutura cadencial. Isso está em pleno acordo com sua localização, por, justamente ser uma Consequente e por finalizar o Período a.

Contudo, a predominância das estratégias vermelha; amarela e verde no gráfico das propostas, apontam que a clara tendência de objetivamente se estabelecer tempi progressivamente menores para cada uma das apresentaçóes da proposta. Ou seja, de fato, é possível detectar um gesto consciente de realce de cada centro tonal ao se isolar este componente (tempo) do parâmetro rítmico de cada evento, quase que associando cada uma das três tonalidades com sua própria personalidade ${ }^{26}$.

\footnotetext{
${ }^{26}$ Ao menos, na Antecedente e Consequente de a, o próprio compositor já o faz, posto que as elabora com texturas contrastantes.
} 


\section{Considerações finais}

Após a análise e discussão dos dados observou-se que as estratégias interpretativas adotadas pelos intérpretes - no que diz respeito à manipulação agógica - operam em, ao menos, duas camadas interdependentes. Uma que propóe variaçóes de andamento na proposta e outra na estrutura maior, a Frase (Antecedente ou Consequente). Situações como aceleração do tempo da estrutura cadencial de forma a "devolver" o tempo "roubado", a essência do Rubato (não obstante a essa aceleração ser em direção a uma cadência estrutural e marcada com uma fermata, como no caso da Consequente de a) foram verificadas, assim como estratégias opostas a essa.

Das trinta interpretaçóes, dezessete mantiveram a mesma estratégia nas duas camadas, representando aproximadamente $57 \%$, o que indica que a estratégia inversa também representa uma proporção significativa. Mesmo assim, destas dezessete, nove ocorreram nas décadas de 1990 e 2000, apontando para uma forte tendência.

A quantidade de estratégias por década também revelou que a década de 2000, a da virada do milênio e do século, teve uma configuração completamente distinta tanto da década de 1980 (onde se observou a maior variedade de estratégias) quanto da de 2010, onde foi verificado um retorno ao padrão que se delineou entre as décadas de 1960 a 1990. Esse padrão é mais claramente visualizado na comparação entre os andamentos médios das Antecedentes.

Por fim, verificou-se também um discreto, porém progressivo decréscimo do andamento médio ao longo das décadas, mais perceptível e mais pronunciado na análise dos andamentos das Antecedentes completas.

Mais estudos acerca deste tema são necessários para conclusões mais abrangentes, contudo, é possível inferir que há, de fato alguma relação entre o andamento médio/estratégia interpretativa e a época da gravação. 


\section{REFERÊNCIAS}

CARRASCO, Claudiney. 1992. "Música e Dramaturgia: Um Estudo em Forma Sonata”. Revista Música, São Paulo, v.3, n.136-172.

FRASER, Alan. The craft of Piano playing. Lanham, Maryland and Oxford: Scarecrow press. 2003. GJERDINGEN, Robert. Music in the Galant Style. New York, Oxford University Press, 2007.

HASLAM, W. E. Style in Singing. Capítulo III. Disponível em http://www.gutenberg.org/cache/epub/21400/pg21400.txt. New York: G. Schirmer,1911

LEIMER, Karl; GIESEKING, Walter. Ritmica, dinamica, pedal y otros problemas de la ejecución pianistica. Ricordi, Buenos Aires, 1938.

LHEVINNE, Joseph. Basic Principles in Pianoforte Playing. Philadelphia: Presser, 1924.

PADEREVSKI, Jan Ignacy. Tempo Rubato. Polish Music Journal, Vol. 4; No. 1; Summer 2001.

PARNCUTT, Richard. Harmony: A Psychoacoustical Approach. Berlin: Springer-Verlag, 1989.

PERSICHETTI, Vincent. XXth Century. Harmony: Creative Aspects and Practice. New York: W. W. Norton \& Co., 1961.

SCHOENBERG, Arnold. Harmonia. Trad. Marden Maluf. São Paulo: UNESP, 2001 [1911]. . Structural Functions of Harmony. New York: W.W. Norton \& co., 1969 [1954].

SCLIAR, Esther. Fraseologia. Edição Revista, ampliada e comentada por Marcos Pupo Nogueira e Caio Giovaneti de Barros. Sem editora, 2019.

\section{PARTITURA}

SCHUBERT, Franz Peter. Allegretto in C Minor D915.1827. IMSLP. Disponível em: http://imslp.org/wiki/Allegretto_in_C_minor,_D.915_(Schubert,_Franz). Acesso em: 15 mar. 2013.

\section{GRAVAÇÕES}

SCHUBERT, Franz Peter. Allegretto em Dó menor para piano D915. Intérprete: Arthur Schnabel (1939). Disponível em: https://www.youtube.com/watch?v=e54b68LWcNo. Acesso em: 28/04/2021. . Allegretto em Dó menor para piano D915. Intérprete: Ray Lev (1947). Disponível em: https://www.youtube.com/watch?v=xBrtRpw9oW4. Acesso em: 28/04/2021. . Allegretto em Dó menor para piano D915. Intérprete: Claudio Arrau (1949). Disponível 
em: https://www.youtube.com/watch?v=UDeqc7W-0VA. Acesso em: 28/04/2021.

. Allegretto em Dó menor para piano D915. Intérprete: Paul Badura-Skoda (1956).

Disponível em: https://www.youtube.com/watch?v=Y-CsYAZb7F0. Acesso em: 28/04/2021.

. Allegretto em Dó menor para piano D915. Intérprete: Bruce Hungerford (1957?).

Disponível em: http://www.youtube.com/watch?v=RbMuGBuS tU. Acesso em: 28/04/2021.

. Allegretto em Dó menor para piano D915. Intérprete: Sviatoslav Richter (1961).

Disponível em: https://www.youtube.com/watch?v=UDeqc7W-0VA. Acesso em: 28/04/2021.

. Allegretto em Dó menor para piano D915. Intérprete: Sviatoslav Richter (1963).

Disponível em: https://www.youtube.com/watch?v=IOtA4Cqw1hM. Acesso em: 28/04/2021.

. Allegretto em Dó menor para piano D915. Intérprete: Wilhelm Kempf (1967) Disponível em: http://www.allmusic.com/album/schubert-wanderer-fantasie-and-other-works-for-pianomw0001373657. Acesso em: 28/04/2021.

. Allegretto em Dó menor para piano D915. Intérprete: Gilbert Schuchter (1968-1970)

Disponível em: http://www.allmusic.com/album/schubert-complete-piano-works-vol-2mw0001363591. Acesso em: 28/04/2021.

. Allegretto em Dó menor para piano D915. Intérprete: Edith Vogel (1978) Disponível em: www.youtube.com/watch?v=s-bY6-Jb4P8. Acesso em: 28/04/2021.

. Allegretto em Dó menor para piano D915. Intérprete: Peter Frankl (1979). Disponível em: https://www.amazon.com/Schubert-Piano-Favorites-Péter-Frankl/dp/B07L9L5VR1. Acesso em: 28/04/2021.

. Allegretto em Dó menor para piano D915. Intérprete: Tessa Birnie (1982). Disponível em: http://www.youtube.com/watch?v=xv8f4hy uDA. Acesso em: 28/04/2021.

. Allegretto em Dó menor para piano D915. Intérprete: Richard Goode (1985). Disponível em: http://www.youtube.com/watch?v=R0AyF-W Xls. Acesso em: 28/04/2021.

. Allegretto em Dó menor para piano D915. Intérprete: Maurizio Polini (1987). Disponível em: http://www.youtube.com/watch?v=oIN66tWItP4. Acesso em: 28/04/2021.

. Allegretto em Dó menor para piano D915. Intérprete: Alfred Brendel (1988). Disponível em: http://www.youtube.com/watch? v=ogSiSCp8RJE. Acesso em: 28/04/2021.

. Allegretto em Dó menor para piano D915. Intérprete: Paul Badura-Skoda (1989).

Disponível em: http://www.prestoclassical.co.uk/r/Genuin/GEN86055. Acesso em: 28/04/2021.

. Allegretto em Dó menor para piano D915. Intérprete: András Schiff(1990). Disponível em: http://www.prestoclassical.co.uk/r/Decca/E4581392. Acesso em: 28/04/2021.

. Allegretto em Dó menor para piano D915. Intérprete: Pascoale Ianonne (1994). Disponível em: http://www.youtube.com/watch?v=bRf5Dq6EpXg. Acesso em: 28/04/2021.

. Allegretto em Dó menor para piano D915. Intérprete: Stephen Kovacevic (1995)

Disponível em: http://www.prestoclassical.co.uk/r/EMI/5034232. Acesso em: 28/04/2021.

. Allegretto em Dó menor para piano D915. Intérprete: Cyprien Katsaris (1996). Disponível 
em: http://www.youtube.com/watch?v=A7sHvR8O4h8. Acesso em: 28/04/2021.

. Allegretto em Dó menor para piano D915. Intérprete: Maria João Pires (1998). Disponível em: http://www.youtube.com/watch?v=KzLqExAzti4. Acesso em: 28/04/2021.

. Allegretto em Dó menor para piano D915. Intérprete: Thomas Larcher (1999). Disponível em: http://www.prestoclassical.co.uk/r/ECM/4651362. Acesso em: 28/04/2021.

. Allegretto em Dó menor para piano D915. Intérprete: Tamara Rumantsiev (2000)

Disponível em: http://www.allmusic.com/album/schubert-piano-sonatas-d157-d279-d568mw0001429068. Acesso em: 28/04/2021.

. Allegretto em Dó menor para piano D915. Intérprete: Alexander Lonquich (2001).

Disponível em: http://www.youtube.com/watch?v=A-aCrTAJ9yY. Acesso em: 28/04/2021.

. Allegretto em Dó menor para piano D915. Intérprete: Michel D’Alberto (2005).

Disponível em: https://www.discogs.com/pt_BR/Schubert-Michel-Dalberto-Piano-Sonatas-

Complete-Sonates-Pour-Piano/release/7796702. Acesso em: 28/04/2021.

. Allegretto em Dó menor para piano D915. Intérprete: David Fray (2009) Disponível em: http://www.youtube.com/watch?v=T5fh-tWzprU. Acesso em: 28/04/2021.

. Allegretto em Dó menor para piano D915. Intérprete: Trudelies Leonhardt (2010)

Disponível em: http://www.youtube.com/watch?v=sXY13fAftso. Acesso em: 28/04/2021.

. Allegretto em Dó menor para piano D915. Intérprete: Paul Lewis (2011) Disponível em: http://www.youtube.com/watch?v=XyJtzibykUw. Acesso em: 28/04/2021.

. Allegretto em Dó menor para piano D915. Intérprete: Paul Lewis (2013) Disponível em: http://www.youtube.com/watch?v=IRmDgePSf9w. Acesso em: 28/04/2021.

. Allegretto em Dó menor para piano D915. Intérprete: Grigory Sokolov (2018) Disponível em: http://www.youtube.com/watch?v=8MgYUoQB hw. Acesso em: 28/04/2021.

. Allegretto em Dó menor para piano D915. Intérprete: Grigory Sokolov (2019) Disponível em: https://www.youtube.com/watch?v=nMBWUKv99pM. Acesso em: 28/04/2021.

\section{SOBRE O AUTOR}

Ernesto Hartmann é Professor Associado da Universidade Federal do Espírito Santo, Membro Permanente do Programa de Pós-Graduação em Música da UFPR e Membro Colaborador do Programa de Pós-Graduação em Música da UFMG. É Bacharel em Piano pela UFRJ, Licenciado em Música pela UCAM, Mestre em Performance pela UFRJ e Doutor em Música - Estruturação e Linguagem Musical pela UNIRIO. Suas pesquisas abrangem as áreas de performance e teoria/análise musical. ORCID: https://orcid.org/0000-0002-9452-5806. E-mail: ernesto.hartmann@pq.cnpq.br 


\section{APÊNDICE}

Tabela com os dados obtidos e estratégias para os extratos

\begin{tabular}{|c|c|c|c|c|c|c|c|}
\hline Ano & Artista & c.1-4 & c.5-8 & $c-29-32$ & c.1-2 & c.5-6 & c. $29-30$ \\
\hline 1939 & Arthur Schnabel & 56 & 52 & 53 & 52 & 53 & 49 \\
\hline 1947 & Ray Lev & 94 & 90 & 98 & 91 & 92 & 98 \\
\hline 1949 & Claudio Arrau & 53 & 51 & 50 & 50 & 49 & 45 \\
\hline 1956 & Badura Skoda & 73 & 70 & 68 & 76 & 69 & 65 \\
\hline 1957 (Aprox.) & Hungerford & 55 & 45 & 44 & 57 & 45 & 47 \\
\hline 1961 & Sviatoslav Richter & 44 & 40 & 42 & 45 & 42 & 41 \\
\hline 1963 & Sviatoslav Richter & 53 & 47 & 47 & 54 & 50 & 48 \\
\hline 1967 & Wilhelm Kempff & 68 & 61 & 57 & 61 & 60 & 57 \\
\hline $1968-1970$ & Gilbert Schuchter & 94 & 85 & 88 & 95 & 86 & 86 \\
\hline 1978 & Edith Vogel & 64 & 62 & 57 & 63 & 63 & 53 \\
\hline 1982 & Tessa Birnie & 56 & 47 & 47 & 55 & 50 & 49 \\
\hline 1985 & Richard Goode & 54 & 50 & 52 & 51 & 51 & 49 \\
\hline 1987 & Maurizio Pollini & 58 & 53 & 49 & 57 & 53 & 50 \\
\hline 1988 & Alfred Brendel & 75 & 62 & 55 & 74 & 63 & 56 \\
\hline 1988 & Paul Badura-Skoda & 65 & 60 & 60 & 63 & 59 & 55 \\
\hline 1990 & Andras Schiff & 65 & 55 & 56 & 66 & 54 & 52 \\
\hline 1994 & Pasquale Iannone & 70 & 61 & 56 & 68 & 60 & 54 \\
\hline 1995 & Stephen Kovacevic & 60 & 56 & 55 & 58 & 53 & 52 \\
\hline 1996 & Cyprien Katsaris & 46 & 41 & 45 & 45 & 39 & 44 \\
\hline 1998 & Maria João Pires & 63 & 61 & 58 & 62 & 59 & 58 \\
\hline 1999 & Thomas Larcher & 54 & 46 & 49 & 54 & 46 & 49 \\
\hline 2000 & Tamara Rumiantsev & 65 & 63 & 63 & 63 & 62 & 60 \\
\hline 2001 & Alexander Lonquich & 57 & 51 & 58 & 55 & 54 & 62 \\
\hline 2005 & Michel Dalberto & 57 & 55 & 57 & 58 & 58 & 58 \\
\hline 2009 & David Fray & 46 & 47 & 46 & 48 & 46 & 45 \\
\hline 2010 & Trudelies Leonhardt & 68 & 62 & 68 & 66 & 64 & 65 \\
\hline 2011 & Paul Lewis & 63 & 53 & 50 & 60 & 47 & 43 \\
\hline 2013 (Brasil, SP, jun/2013) & Paul Lewis & 62 & 58 & 54 & 61 & 52 & 47 \\
\hline 2018 (13 de maio - Amsterdam) & Grigory Sokolov & 48 & 45 & 47 & 47 & 45 & 45 \\
\hline 2019 (24 de julho - Wiesbaden) & Grigory Sokolov & 51 & 48 & 48 & 51,2 & 45,9 & 45 \\
\hline
\end{tabular}

